\title{
Composites Based on Hydroxyapatite and Whey Protein Isolate for Applications in Bone Regeneration
}

\author{
Dagmara Słota ${ }^{1, *}$, Magdalena Głąb ${ }^{1}$, Bożena Tyliszczak ${ }^{1}\left(\mathbb{D}\right.$, Timothy E. L. Douglas ${ }^{2,3}$, Karolina Rudnicka ${ }^{4}(\mathbb{D}$, \\ Krzysztof Miernik $^{1}$, Mateusz M. Urbaniak ${ }^{4}{ }^{(D)}$, Paulina Rusek-Wala ${ }^{4}$ and Agnieszka Sobczak-Kupiec ${ }^{1}$ (D) \\ 1 Faculty of Materials Engineering and Physics, Department of Materials Science, \\ Cracow University of Technology, 31-864 Krakow, Poland; magdalena.glab@doktorant.pk.edu.pl (M.G.); \\ bozena.tyliszczak@pk.edu.pl (B.T.); kmiernik@pk.edu.pl (K.M.); \\ agnieszka.sobczak-kupiec@pk.edu.pl (A.S.-K.) \\ 2 Materials Science Institute (MSI), Lancaster University, Lancaster, UK; t.douglas@lancaster.ac.uk \\ 3 Engineering Department, Lancaster University, Lancaster LA1 4YW, UK \\ 4 Department of Immunology and Infectious Biology, Faculty of Biology and Environmental Protection, \\ University of Lodz, 90-237 Lodz, Poland; karolina.rudnicka@biol.uni.lodz.pl (K.R.); \\ mateusz.urbaniak2@unilodz.eu (M.M.U.); paulina.rusek@unilodz.eu (P.R.-W.) \\ * Correspondence: dagmara.slota@doktorant.pk.edu.pl
}

Citation: Słota, D.; Głąb, M.; Tyliszczak, B.; Douglas, T.E.L.; Rudnicka, K.; Miernik, K.; M. Urbaniak, M.; Rusek-Wala, P.; Sobczak-Kupiec, A. Composites Based on Hydroxyapatite and Whey Protein Isolate for Applications in Bone Regeneration. Materials 2021, 14, 2317.

https://doi.org/10.3390/ma14092317

Academic Editors: Arne Berner and Alessandro Pistone

Received: 11 March 2021

Accepted: 28 April 2021

Published: 29 April 2021

Publisher's Note: MDPI stays neutral with regard to jurisdictional claims in published maps and institutional affiliations.

Copyright: (c) 2021 by the authors. Licensee MDPI, Basel, Switzerland. This article is an open access article distributed under the terms and conditions of the Creative Commons Attribution (CC BY) license (https:// creativecommons.org/licenses/by/ $4.0 /)$.

\begin{abstract}
Hydroxyapatite (HAp) is a bioactive ceramic with great potential for the regeneration of the skeletal system. However, its mechanical properties, especially its brittleness, limit its application. Therefore, in order to increase its ability to transmit stresses, it can be combined with a polymer phase, which increases its strength without eliminating the important aspect of bioactivity. The presented work focuses on obtaining organic-inorganic hydrogel materials based on whey protein isolate (WPI) reinforced with nano-HAp powder. The proportion of the ceramic phase was in the range of $0-15 \%$. Firstly, a physicochemical analysis of the materials was performed using XRD, FT-IR and SEM. The hydrogel composites were subjected to swelling capacity measurements, potentiometric and conductivity analysis, and in vitro tests in four liquids: distilled water, Ringer's fluid, artificial saliva, and simulated body fluid (SBF). The incubation results demonstrated the successful formation of new layers of apatite as a result of the interaction with the fluids. Additionally, the influence of the materials on the metabolic activity according to ISO 10993-5:2009 was evaluated by identifying direct contact cytotoxicity towards L-929 mouse fibroblasts, which served as a reference. Moreover, the stimulation of monocytes by hydrogels via the induction of nuclear factor (NF)- $\mathrm{kB}$ was investigated. The WPI/HAp composite hydrogels presented in this study therefore show great potential for use as novel bone substitutes.
\end{abstract}

Keywords: hydroxyapatite; ceramic biomaterials; whey protein isolate; composites

\section{Introduction}

Advances in civilization's changes in lifestyle and aging societies in the developed world are resulting in an increasing occurrence of the so-called diseases of the 21st century. These non-communicable diseases (NCDs) are chronic, lifestyle-related and non-infectious to others. There are four main NCDs, namely cardiovascular diseases (such as heart attack and stroke), cancer, chronic respiratory diseases (such as chronic obstructive pulmonary disease and asthma) and diabetes. However, hypertension, Alzheimer's disease and osteoporosis are also increasingly common. According to the WHO 2014 report, noncommunicable diseases are responsible for almost $70 \%$ of premature deaths $[1,2]$. For the studies presented, osteoporosis is particularly significant, as it is an enormous and growing public health problem and consequently the most common skeletal ailment. It is estimated that currently more than 200 million people are affected, and that it causes over 8.9 million fragility fractures each year $[3,4]$. It affects every third woman and every fifth man aged 
over 50 . The higher prevalence in women is related to the change in hormone metabolism after the menopause, and due to lower levels of estrogen [5]. It is a progressive disease, manifested by a decrease in bone density, which weakens it as well as increasing the risk of fracture. After a bone break, chronic pain and reduced ability to perform basic activities may occur [6]. The treatment of osteoporosis uses known antiresorptive drugs and new anabolic options which are being constantly proposed. However, concerns regarding side effects as well as long-term effects remain under-investigated, and contribute to the substantial under-treatment of patients [7]. Therefore, new, innovative methods of treatment and prevention are being sought, preferably those containing active components and exhibiting bioactivity towards damaged tissues.

A widely used material with impressive bioactive properties and with a high chemical and crystallographic similarity to the inorganic phase of bone is hydroxyapatite (HAp). It is applied as an orthopedic biomaterial and in dentistry to replace hard tissues. Particularly interesting is its biocompatibility, ability to bind to natural bone, its porous structure and its ability to enable the growth of the surrounding tissues [8,9]. The feature that distinguishes HAp from other materials used in implantology is osteoinduction, a process that induces osteogenesis, leading to the formation of new bone $[10,11]$. This is an extremely important aspect in the treatment of osteoporosis. In the osteoporotic state, there is an excessive activity of osteoclasts, the bone-degrading cells, resulting in skeletal destruction and a dangerous loss of bone mass $[12,13]$. HAp improves the response of osteoblasts, thus maintaining the balance between osteoblasts and osteoclasts $[14,15]$. However, HAp, despite its advantages, has several disadvantages that limit its usability. These are brittleness, low tensile strength and fracture toughness. Therefore, such an implant will not be able to withstand high stress and will be destroyed quickly [16]. The solution to these problems, while maintaining the bioactive character of the material, is to create a composite with an elastic phase, which exhibits a higher flexibility than HAp [17].

One of the types of polymer scaffolds with several potential advantages in bone regeneration are hydrogels [18]. These consist of hydrophilic polymer chains arranged in a three-dimensional (3D) space. The hydrophilic nature of the scaffolds allows it to provide a nutritional environment suitable for the growth of endogenous cells. Due to their structural similarity to the natural extracellular matrix (ECM), they show a promising ability to encapsulate drugs, cells or bioactive particles. Thus, they function as carriers of active substances which can facilitate local controlled release [19-21]. Hydrogels are characterized by high absorbency, tunable viscoelasticity, and permeability to oxygen and essential nutrients. Furthermore, and most importantly, they show excellent integration with surrounding tissues, which reduces the chances of inflammatory reactions [22]. However, traditional hydrogels are bulk gels consisting of inert polymers that are not bioactive and have low mechanical strength [23]. Therefore, a combination of a hydrogel with a hydroxyapatite phase would make it possible to obtain a composite with enhanced strength through the ability of the polymer to carry the stresses, and with superior bioactive properties thanks to the presence of the HAp phase.

Whey is a by-product of the cheese production process, obtained from bovine milk [24]. The whey protein isolated from it contains peptides, glycopeptides and other protein glycoconjugates with immunomodulating properties such as $\alpha$-lactalbumins, $\beta$-lactoglobulins and components promoting bone mineralization such as calcium, lactates, and phosphates $[25,26]$. Commercially processed whey protein occurs in three main forms, as a concentrate (WPC), an isolate (WPI) and a hydrolysate (WPH) [27]. The following studies were based on WPI. WPI is a processed product, purified to remove fat and lactose, containing over $90 \%$ protein. Purification can be carried out by microfiltration followed by ultrafiltration and spray drying or ion exchange, after which the product concentration and spray drying takes place [28]. WPI demonstrates good water solubility and undergoes the process of gelation after heating. This results in the formation of protein bonds inside the structure of the hydrogel, which eliminates the need for the use of additional chemical crosslinking agents [29]. Due to its impressive biocompatibility and sensitivity to $\mathrm{pH}, \mathrm{WPI}$ 
hydrogel can potentially be used as a carrier of biomolecules, or as a drug delivery system for the controlled release of medicines [30]. Therefore, WPI appears to be a suitable material from which to create a modified hydrogel with potential applications in tissue regeneration.

This work is devoted to the fabrication and in vitro characterization of composite hydrogels based on WPI protein and hydroxyapatite. In order to precisely analyze the obtained biomaterials, they were subjected to incubation tests in simulated body fluid (SBF), artificial saliva and Ringer's fluid. Furthermore, cell biological analysis was performed by analyzing the cytotoxicity against mouse fibroblast cell line L-929 and the monocyte activation towards THP1-Blue ${ }^{\mathrm{TM}}$ NF- $\mathrm{kB}$ cells derived from the THP-1 human monocytic leukemia cell line. To the best of our knowledge, there are no studies on the preparation, physicochemical properties and bioactivity of the materials obtained in the manner presented in this study.

\section{Materials and Methods}

\subsection{Materials}

WPI (BiPRO) containing 97.7\% protein and 75\% $\beta$-lactoglobulins (according to the manufacturer's specification) was purchased from Davisco Foods International Inc (Eden Prairie, MN, USA). The calcium acetate monohydrate $\left(\mathrm{Ca}\left(\mathrm{CH}_{3} \mathrm{CO}_{2}\right)_{2} \cdot \mathrm{H}_{2} \mathrm{O}\right)$, sodium phosphate dibasic $\left(\mathrm{Na}_{2} \mathrm{HPO}_{4}\right)$, ammonium phosphate monobasic $\left(\mathrm{NH}_{4} \mathrm{H}_{2} \mathrm{PO}_{4}\right)$, calcium nitrate tetrahydrate $\left(\mathrm{Ca}\left(\mathrm{NO}_{3}\right)_{2} \cdot 4 \mathrm{H}_{2} \mathrm{O}\right)$ and ammonia water $\left(\mathrm{NH}_{4} \mathrm{OH}, 25 \%\right)$ used in the HAp synthesis were obtained from Sigma-Aldrich (Darmstadt, Germany). For biological assay L-929 (CCL-1 ${ }^{\mathrm{TM}}$ ), mouse fibroblasts (ATCC, Manassas, VA, USA), THP1-Blue ${ }^{\mathrm{TM}}$ NF- $\mathrm{kB}$ cells (InvivoGen, San Diego, CA, USA), fetal bovine serum (FBS) (HyClone Cytiva, Marlborough, MA, USA), penicillin, strepto-mycin, 3-(4,5-dimethylthiazol-2-yl)-2,5-diphenyltetrazolium bromide (MTT), dimethyl sulfoxide, monocytes stimulated with $\beta$-glucan from Saccharomycces cerevisiae (S. cerevisiae) (Sigma-Aldrich, Darmstadt, Germany), trypsin-EDTA solution (Gibco, Waltham, MA, USA), 4-(2-hydroxyethyl)-1-piperazineethanesulfonic acid (HEPES), blasticidin and QUANTI-Blue ${ }^{\mathrm{TM}}$ (InvivoGen) were used.

\subsection{Preparation of Hydroxyapatite}

HAp, representing the ceramic phase of the composite hydrogels, was obtained via two wet precipitation methods. For this purpose, in the first method (method A), performed at room temperature, $80 \mathrm{~mL} \mathrm{NH}_{4} \mathrm{H}_{2} \mathrm{PO}_{4}(0.36 \mathrm{~mol} / \mathrm{L})$ was added to $520 \mathrm{~mL}$ distilled water, and then a few drops of ammonia water were added in order to obtain a $\mathrm{pH}$ value $>10$. Then, $200 \mathrm{~mL} \mathrm{Ca}\left(\mathrm{NO}_{3}\right)_{2}$ solution at a concentration of $0.6 \mathrm{~mol} / \mathrm{L}$ was added dropwise under constant stirring at a rate of $1 \mathrm{drop} / \mathrm{s}$. The second method (method B) was performed at boiling point. A few drops of ammonia water were added to $80 \mathrm{~mL} \mathrm{Na} 2 \mathrm{HPO}_{4}$ solution at a concentration of $0.32 \mathrm{~mol} / \mathrm{L}$ in order to obtain an alkaline $\mathrm{pH}$ value $(\mathrm{pH}>10)$ of the mixture. Then, $520 \mathrm{~mL}$ distilled water was added and the mixture was heated to boiling point. When the boiling point was reached, $200 \mathrm{~mL}\left(\mathrm{CH}_{3} \mathrm{COO}\right)_{2} \mathrm{Ca}(0.128 \mathrm{~mol} / \mathrm{L})$ was added dropwise under constant stirring at a rate of 1 drop/s. After each reaction was completed, the obtained HAp powder was aged for $24 \mathrm{~h}$ at room temperature, and then the sludge was washed thoroughly with distilled water to achieve a neutral $\mathrm{pH}$ and finally dried at $104^{\circ} \mathrm{C}$ for $4 \mathrm{~h}$ in a laboratory dryer.

\subsection{Preparation of the Composite Hydrogels}

The WPI-based hydrogel was obtained as a result of a gelation reaction. In total, $60 \mathrm{~mL}$ distilled water was added to $40 \mathrm{~g}$ WPI by stirring intensively on a magnetic stirrer. In this way, a WPI solution of $40 \%(w / w)$ concentration was obtained. The reaction was carried out at room temperature. After the complete dissolution of the WPI, the solution was left for approximately $2 \mathrm{~h}$ in order to allow the resulting foam to settle.

In order to obtain stable composites, the ceramic phase $\mathrm{A}$, at three different concentrations (5\%, 10\%, 15\% weight percentages) was added to Eppendorf tubes containing the WPI solution. All of the samples were quickly mixed using a vortexer for approximately 
$2 \mathrm{~min}$ in order to distribute the phases evenly throughout the volume. Then, to prevent the sedimentation and stabilization of the composites, the Eppendorf tubes were placed in a water bath at $90^{\circ} \mathrm{C}$ for $7 \mathrm{~min}$. In this way, cylindrical composites with a diameter of $1 \mathrm{~cm}$ and a height of $3 \mathrm{~cm}$ were obtained. The operations were repeated for ceramic phase $B$. WPI hydrogels without HAp were also synthesized as control samples. All of the samples were sterilized using a UV lamp. The compositions of each composite are presented in Table 1.

Table 1. Percentage share of ceramics in hydrogels WPI/HAp.

\begin{tabular}{cc}
\hline Sample Symbol & Ceramic Content (\%) \\
\hline WPI 0 & - \\
WPI A5 & 5 \\
WPI A10 & 10 \\
WPI A15 & 15 \\
WPI B5 & 5 \\
WPI B10 & 10 \\
WPI B15 & 15 \\
\hline
\end{tabular}

\subsection{X-ray Diffraction Analysis}

The phase composition and crystallinity of the two kinds of HAp powders were determined using the X-ray diffraction (XRD) method. For this purpose, a Rigaku SmartLab X-ray Difractometer (Wilmington, MA, USA) was used. The measurement was performed at a voltage of $40 \mathrm{kV}$ and $30 \mathrm{~mA}$ in a $2 \theta$ range of $10-60^{\circ}$ and at a step size of $0.002^{\circ} 2 \theta$.

\subsection{Fourier Transform Infrared Spectroscopy Analysis}

Fourier transform infrared spectroscopy (FT-IR) was used to analyze the hydroxyapatite and the composition of hydrogels before and after incubation, and to determine the functional groups present in the materials. The Thermo Scientific Nicolet iS5 FTIR spectrophotometer equipped with iD7 ATR (Loughborough, UK) was used for this purpose. The device was equipped with a high-performance, reflective optical system and was supplied with a monolithic diamond crystal ATR. This crystal enabled a high optical contact between the sample and the diamond, which lead to a good resolution. The spectra were recorded in the wavelength range $4000-400 \mathrm{~cm}^{-1}$, at room temperature.

\subsection{Incubation In Vitro}

The obtained dried hydrogel samples with an initial mass of $1 \mathrm{~g}$ were incubated for 14 days in artificial biological fluids and distilled water at a constant temperature of $37^{\circ} \mathrm{C}$. Three solutions-namely artificial saliva, SBF and Ringer's solution-were prepared; their compositions are shown in Table 2, Table 3, Table 4. The ingredients were mixed according to a specified order, and each component was added after the complete dissolution of the previous ones. The SBF solution was prepared at a constant temperature of $36 \pm 1.5^{\circ} \mathrm{C}$.

Table 2. Composition of the Ringer's solution.

\begin{tabular}{cc}
\hline Component & Amount (g/L) \\
\hline $\mathrm{NaCl}$ & 8.600 \\
$\mathrm{KCl}$ & 0.300 \\
$\mathrm{CaCl}_{2} \cdot \mathrm{H}_{2} \mathrm{O}$ & 0.480 \\
\hline
\end{tabular}


Table 3. Composition of the artificial saliva.

\begin{tabular}{cc}
\hline Component & Amount (g/L) \\
\hline $\mathrm{NaCl}$ & 0.400 \\
$\mathrm{KCl}$ & 0.400 \\
$\mathrm{CaCl}_{2} \cdot \mathrm{H}_{2} \mathrm{O}$ & 0.795 \\
$\mathrm{Na}_{2} \mathrm{HPO}_{4} \cdot \mathrm{H}_{2} \mathrm{O}$ & 0.780 \\
$\mathrm{Na}_{2} \mathrm{~S} \cdot 9 \mathrm{H}_{2} \mathrm{O}$ & 0.005 \\
$\mathrm{CH}_{4} \mathrm{~N}_{2} \mathrm{O}$ & 1.000 \\
\hline
\end{tabular}

Table 4. Composition of the SBF.

\begin{tabular}{cc}
\hline Component & Amount (g/L) \\
\hline $\mathrm{NaCl}$ & 8.035 \\
$\mathrm{NaHCO}$ & 0.355 \\
$\mathrm{KCl}$ & 0.225 \\
$\mathrm{~K}_{2} \mathrm{HPO}_{4} \cdot 3 \mathrm{H}_{2} \mathrm{O}$ & 0.231 \\
$\mathrm{MgCl}_{2} \cdot 6 \mathrm{H}_{2} \mathrm{O}$ & 0.311 \\
$1 \mathrm{M} \mathrm{HCl}^{\mathrm{HCl}}$ & $39 \mathrm{~mL}$ \\
$\mathrm{CaCl}_{2}$ & 0.292 \\
$\mathrm{Na}_{2} \mathrm{SO}_{4}$ & 0.072 \\
Tris & 6.118 \\
\hline
\end{tabular}

\subsection{Swelling Capacity}

The swelling capacity of the composites was studied in order to determine the amount of fluid that they could absorb at a given time. The process was carried out in distilled water and selected artificial biological fluids. The samples were discs, which were cut out of the prepared composite hydrogel (see Section 2.3). The discs had an initial mass of $1 \mathrm{~g}$. The swelling ratio $\left(S_{w}\right)$ was calculated using the following Equation (1):

$$
S_{w}=\frac{\left(W_{t}-W_{0}\right)}{W_{0}} \cdot 100 \%
$$

where $W_{t}$ is the weight of the swollen hydrogel sample and $W_{0}$ is the initial sample weight [31].

\subsection{Morphology Analysis}

The analysis of the surface morphology by scanning electron microscopy was performed in order to determine the topography of the hydroxyapatite and hydrogel composites before and after the incubation period. The study enabled the detection of potential deposits formed on the surface of the samples as a result of interaction with individual ions of artificial biological fluids.

A Jeol 5510LV Scanning Electron Microscope with a EDS IXRF System detector (Freising, Germany) was used for this purpose. Before the measurement, the samples were thoroughly dried at $36.5^{\circ} \mathrm{C}$ for $48 \mathrm{~h}$ and sputtered with a nano-layer of gold.

\subsection{Stability Measurements}

The stability of the emulsions was evaluated using MultiScan MS20 DataPhysics Instruments (Charlotte, NC, USA). This technique consisted in detecting the transmission of monochromatic NIR radiation at $100 \mathrm{~nm}$, using a transmission detector that measures the radiation transmitted by the sample. The measurement enabled the determination of both the descent rate of the particles in the suspension and their average diameter. The sedimentation rate of hydroxyapatite particles in water and WPI solution was determined. The study was based on the observation of the behavior of the HAp suspension over time. The rate of sedimentation and the obtained transmission provides information on the homogeneity of the substance. The rate of sedimentation varies depending on the 
monodispersing or polydispersing nature of the suspension. The measurements were carried out at $25^{\circ} \mathrm{C}$.

\subsection{In Vitro Cytocompatibility \\ 2.10.1. Cell Culture}

The influence of composite hydrogels on cell metabolic activity was assessed according to ISO 10993-5:2009 (Biological evaluation of medical devices-Part 5: Tests for in vitro cytotoxicity) toward reference L-929 (CCL-1 $\left.{ }^{\mathrm{TM}}\right)$ mouse fibroblasts obtained from the American Type Culture Collection. Prior to the experiments, fibroblasts were cultured in Roswell Park Memorial Institute (RPMI)-1640 medium supplemented with 10\% heat-inactivated fetal bovine serum (FBS) and standard antibiotics: penicillin $(100 \mathrm{U} / \mathrm{mL})$ and streptomycin $(100 \mu \mathrm{g} / \mathrm{mL})$. The cells were incubated at $37^{\circ} \mathrm{C}$ in a $5 \% \mathrm{CO}_{2}$ atmosphere in a humidified cell incubator until the formation of the cell monolayer. For the subculturing, confluent cell monolayers were detached from the bottom of the culture flasks with $0.25 \%$ trypsin-EDTA solution and resuspended in RPMI-1640 medium. Following the centrifugation $(400 \times g$, $10 \mathrm{~min}$ ), the cell pellet was resuspended in fresh medium, and the cell viability and density were assessed using a counting Bürker chamber (Blaubrand, Wertheim, Germany) and a trypan blue exclusion assay (Avantor Performance Materials, Gliwice, Poland).

\subsubsection{Direct Contact Cytotoxicity Assay}

The L-929 fibroblasts adjusted to a density of $2 \times 10^{5}$ cells $/ \mathrm{mL}$ were transferred into 96-well culture plates (20,000 cells / per well) (Nunclon Delta Surface, Nunc, Rochester, NY, USA) and incubated overnight in standard conditions at $37^{\circ} \mathrm{C}$. After incubation, the L-929 cell cultures were observed using an inverted contrast phase microscope (Motic AE2000, Xiamen, China) in order to confirm that the confluent monolayer had formed. Suspensions of the investigated pieces of composite hydrogels (WPI0-the control sample, WPI A5, WPI A10, WPI A15, WPI B5, WPI B10, WPI B15) corresponding to one-tenth of the well surface area were prepared under sterile conditions. The cell culture medium was replaced with $100 \mu \mathrm{L}$ fresh RPMI-1960 medium, and pieces of the composite hydrogels were added to selected wells in six replicates. The cell cultures in the medium without the tested samples were used as a positive control for cell viability. After overnight incubation, the condition of the cell monolayers was verified under an inverted contrast phase microscope. In order to quantify the cell viability, $20 \mu \mathrm{L}$ 3-(4,5-dimethylthiazol-2-yl)-2,5-diphenyltetrazolium bromide (MTT) was added to each well and incubation was carried out for another $4 \mathrm{~h}$. In the next step, the plates were centrifuged at $450 \times g$ for $10 \mathrm{~min}$, the remaining liquid was removed, and the formazan crystals were dissolved with $100 \mu \mathrm{L}$ dimethyl sulfoxide. The absorbance was determined spectrophotometrically using the Multiskan EX plate reader (Thermo Scientific, Waltham, MA, USA) at $570 \mathrm{~nm}$.

\subsection{Monocyte Activation}

THP1-Blue ${ }^{\mathrm{TM}} \mathrm{NF}-\mathrm{KB}$ cells derived from the human THP-1 monocyte cell line were used to examine whether the WPI present in the hydroxyapatite and hydrogels stimulate monocytes by the induction of nuclear factor NF- $\mathrm{kB}$. The primary cell cultures were passaged two times in RPMI 1640 medium supplemented with heat-inactivated $10 \%$ FBS, $25 \mathrm{mM}$ 4-(2-hydroxyethyl)-1-piperazineethanesulfonic acid (HEPES), penicillin/streptomycin solution $(100 \mathrm{U} / \mathrm{mL} ; 100 \mu \mathrm{g} / \mathrm{mL}), 2 \mathrm{mM}$ glutamine and $100 \mu \mathrm{g} / \mathrm{mL}$ normocin. Then, THP1-Blue ${ }^{\mathrm{TM}}$ NF-KB monocytes were re-cultured in selective RPMI 1640 medium additionally containing $10 \mu \mathrm{g} / \mathrm{mL}$ blasticidin in a density below $1 \times 10^{6}$ cells $/ \mathrm{mL}$ at $37^{\circ} \mathrm{C}$, and in a humidified atmosphere containing $5 \% \mathrm{CO}_{2}$. The experiments were conducted as described previously $[32,33]$. Briefly, monocytes were adjusted to the optimal density $\left(1 \times 10^{6}\right.$ cells $\left./ \mathrm{mL}\right)$ and distributed equally in each well of the 96 -well plate $(200 \mu \mathrm{L} /$ well $)$. Then, as described in Section 2.10.2, hydroxyapatites and sections of the hydrogels were added to selected wells, in four replicates. The following positive and negative controls of NF- $\mathrm{kB}$ activation were included: monocytes stimulated with $\beta$-glucan from Saccharomycces 
cerevisiae (S. cerevisiae) and monocytes incubated in complete medium, respectively. In order to quantify the monocyte activation, $20 \mu \mathrm{L}$ of each supernatant was transferred to and mixed with $180 \mu \mathrm{L}$ QUANTI-Blue ${ }^{\mathrm{TM}}$ substrate reagent to detect the activity of secreted embryonic alkaline phosphatase (SEAP). The absorbance was measured after $4 \mathrm{~h}$ incubation at $650 \mathrm{~nm}$ on the Multiskan EX plate reader (Thermo Scientific, Waltham, MA, USA).

\section{Results}

\subsection{X-ray Diffraction Analysis of HAp}

The result of the XRD analysis of the powders consisted of two diffractograms, which are shown in Figure 1a. Although the obtained diffractograms vary considerably, especially in the intensity of the individual bands, the analysis showed that both ceramic materials were pure, and the only phase identified by X-rays in the examined powders was HAp. The graph for powder A obtained by $\mathrm{X}$-ray analysis suggests that the substance obtained was more amorphous than for powder B, which appeared to be more crystalline, because of the more intense background peaks. According to the International Center for Diffraction Data (No. 9-432), XRD reflections were assigned to the hexagonal structure of HAp [34].

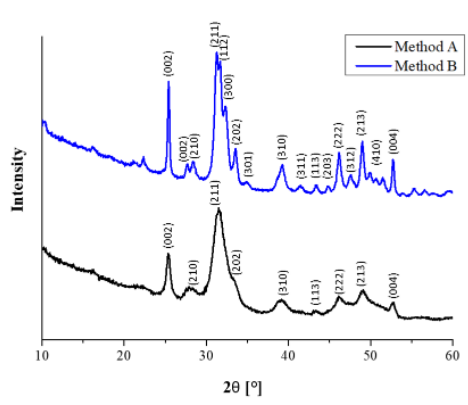

(a)

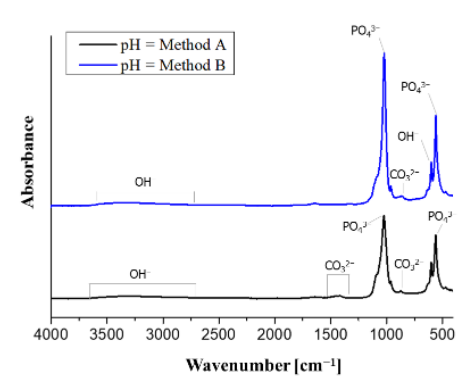

(b)

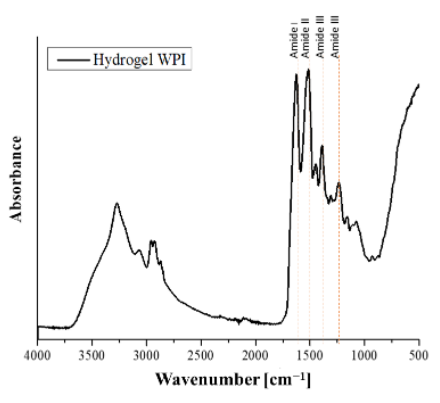

(c)

Figure 1. (a) XRD diffractograms of hydroxyapatite obtained by methods A and B; (b) FTIR spectra of hydroxyapatite obtained by methods A and B; (c) FT-IR spectra of WPI hydrogel.

\subsection{Fourier-Transform Infrared Spectroscopy Analysis \\ 3.2.1. FT-IR Analysis of HAp}

The spectroscopic spectra of the hydroxyapatite powders obtained are shown in Figure $1 b$. There are many chemical groups in the FTIR spectrum of HAp that are characteristic for this material. Infrared absorption spectrum analysis showed the presence of phosphate groups in both investigated HAp powders, which is evidenced by clear bands in the range 550-1050 $\mathrm{cm}^{-1}$. For sample A, the double band in the wavelength range $555 \mathrm{~cm}^{-1}$ to $565 \mathrm{~cm}^{-1}$ is associated with a triply degenerated bending mode of the $\mathrm{O}-\mathrm{P}-\mathrm{O}$ in the $\mathrm{PO}_{4}{ }^{3-}$ groups, which occupied two sites in the crystal lattice; in material $\mathrm{B}$, the values of $600 \mathrm{~cm}^{-1}$ and $565 \mathrm{~cm}^{-1}$ are corresponding. The presence of sharp and splitting peaks at this range indicated a high degree of crystallinity, which is particularly noticeable for HAp B [35]. Characteristic for HAp, the intense peaks associated with asymmetrical $\mathrm{P}-\mathrm{O}$ tensile vibrations are attributed to the values $965 \mathrm{~cm}^{-1}$ and $1026 \mathrm{~cm}^{-1}$ for material B and $1011 \mathrm{~cm}^{-1}$ for sample A [36]. The weak peaks of $1620 \mathrm{~cm}^{-1}$, shown in both graphs, are more intense in $\mathrm{B}$, corresponding to the presence of $\mathrm{OH}^{-}$associated with the HAp molecules [35]. The wide peak for values $2900-3640 \mathrm{~cm}^{-1}$ indicate the occurrence of valence vibrations of the $\mathrm{OH}^{-}$group; these are also present in $\mathrm{B}, 2900-3540 \mathrm{~cm}^{-1}$, although they possess less intensity. Those broad absorption bands are attributed to the presence of $\mathrm{H}_{2} \mathrm{O}$ associated with the HAp molecules [37]. However, in sample A, there are peaks that do not coincide with diagram B. These differences are probably caused by the use of other substrates and a different way of performing the synthesis. These are values at $1320 \mathrm{~cm}^{-1}$ and $1480 \mathrm{~cm}^{-1}$, the presence of which is caused by atmospheric synthesis. They 
suggest the presence of a bending mode of carbon ions [38]. The respective peaks with their assigned function groups are summarized in Table 5.

Table 5. IR bad assignment of HAp.

\begin{tabular}{|c|c|c|}
\hline Type of Hydroxyapatite & Wavenumber $\left(\mathrm{cm}^{-1}\right)$ & Peak Assignment \\
\hline \multirow{8}{*}{ HAp A } & $2900-3640$ & Band corresponding to $\mathrm{H}_{2} \mathrm{O}$ absorption \\
\hline & 1620 & Band corresponding to $\mathrm{H}_{2} \mathrm{O}$ absorption \\
\hline & 1480 & Carbonate ions \\
\hline & 1320 & Carbonate ions \\
\hline & 1011 & Asymmetric Stretching mode of $\mathrm{P}-\mathrm{O}$ \\
\hline & 840 & Carbonate ions \\
\hline & 565 & Triply degenerate Bending of $\mathrm{PO}_{4}{ }^{3-}(\mathrm{O}-\mathrm{P}-\mathrm{O})$ \\
\hline & 555 & Triply degenerate bending of $\mathrm{PO}_{4}{ }^{3-}(\mathrm{O}-\mathrm{P}-\mathrm{O})$ \\
\hline \multirow{7}{*}{ HAp B } & $2900-3540$ & Band corresponding to $\mathrm{H}_{2} \mathrm{O}$ absorption \\
\hline & 1620 & Band corresponding to $\mathrm{H}_{2} \mathrm{O}$ absorption \\
\hline & 1026 & Asymmetric Stretching mode of $\mathrm{P}-\mathrm{O}$ \\
\hline & 965 & Asymmetric Stretching mode of $\mathrm{P}-\mathrm{O}$ \\
\hline & 845 & Carbonate ions \\
\hline & 600 & Triply degenerate bending of $\mathrm{PO}_{4}{ }^{3-}(\mathrm{O}-\mathrm{P}-\mathrm{O})$ \\
\hline & 565 & Triply degenerate bending of $\mathrm{PO}_{4}{ }^{3-}(\mathrm{O}-\mathrm{P}-\mathrm{O})$ \\
\hline
\end{tabular}

\subsubsection{FT-IR Analysis of the WPI Matrix and WPI/HAp Composites}

The FT-IR analysis was performed both for the composites with different contents of the ceramic phase and for WPI hydrogel without the addition of HAp. The results of the analysis are presented in the Figure 2. In the case of unmodified WPI hydrogel (Figure 1c), a wide absorption band was observed in the wavenumber range $3600-3000 \mathrm{~cm}^{-1}$ (with a maximum at about $3278 \mathrm{~cm}^{-1}$ ), which was assigned to stretching vibrations of the $-\mathrm{OH}$ and $-\mathrm{NH}$ groups [39]. Then, in the range $3000-2850 \mathrm{~cm}^{-1}$, a band of relatively low intensity corresponding to $\mathrm{C}-\mathrm{H}$ stretching vibrations of carbonyl groups of triglycerides (lipids present in dairy products) was identified. The next bands are associated with peptide bonds, and are characteristic of whey proteins. The maximum at $1632 \mathrm{~cm}^{-1}$ is a characteristic band of the primary amide group of proteins $\left(-\mathrm{CO}-\mathrm{NH}_{2}\right)$. The band at $1520 \mathrm{~cm}^{-1}$ corresponds to the secondary amide group of proteins $(-\mathrm{CO}-\mathrm{NH})$ [40]. The range $1400-1200 \mathrm{~cm}^{-1}$ was attributed to the amide III [41]. The observed characteristic band at around $1040 \mathrm{~cm}^{-1}$ was assigned to the stretching of $\mathrm{C}-\mathrm{O}$ vibrations [42]. These vibrations are most probably derived from saccharides present in whey protein, which suggests that, despite purification, traces of lactose were still present in the WPI. The characteristic vibration range for the specific groups is presented in Table 6. 


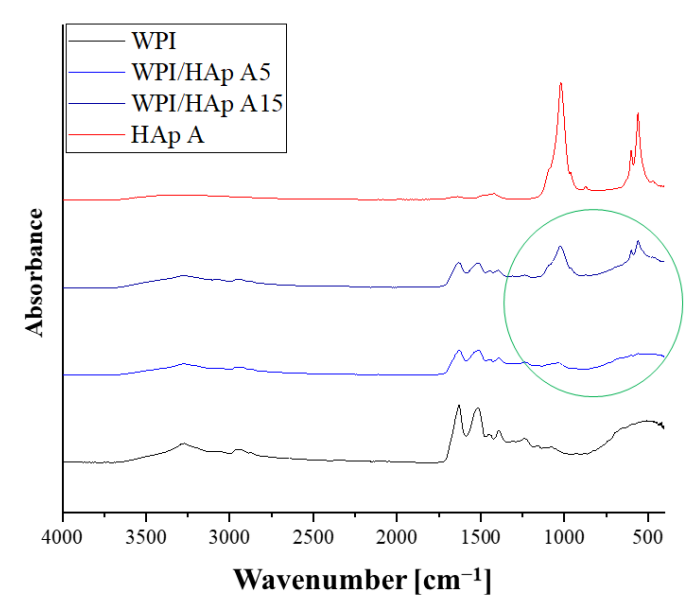

(a)

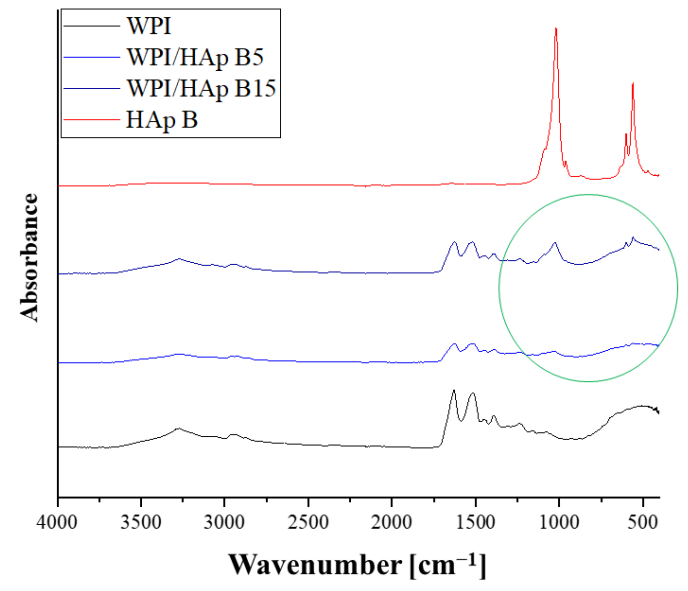

(b)

Figure 2. FT-IR spectra of composites with different Hap contents indicated by a green circle: (a) WPI/HAp A; (b) WPI/HAp B.

Table 6. IR band assignment of WPI.

\begin{tabular}{cc}
\hline Wavenumber $\left(\mathbf{c m}^{-\mathbf{1}}\right)$ & Peak Assignment \\
\hline $3600-3000$ & Stretching vibrations of $-\mathrm{OH}$ and $-\mathrm{NH}$ \\
$3000-2850$ & Stretching vibrations of $\mathrm{C}-\mathrm{H}$ \\
1632 & Amide I \\
1520 & Amide II \\
$1400-1200$ & Amide III \\
1040 & Stretching vibrations of C-O \\
\hline
\end{tabular}

The FT-IR spectra of composites containing different amounts of the ceramic phase are presented in Figure 2a for hydroxyapatite obtained by method A, and in Figure $2 b$ for hydroxyapatite obtained by method B. The analysis was conducted for composites containing 5 and $15 \%$ ceramic phases. The obtained results were compared with the spectrum of pure hydroxyapatite and unmodified WPI hydrogel. In the graphs, a green circle indicates the presence of groups characteristic of hydroxyapatite in the composite material. In the case of composites containing a $5 \%$ ceramic phase, a new absorption band in the wavelength range $1010-1025 \mathrm{~cm}^{-1}$ was observed on the spectrum. This band has a relatively low intensity, and the range corresponds to asymmetrical $\mathrm{P}-\mathrm{O}$ tensile vibrations. For a composite containing 15\% hydroxyapatite, a new band was also observed in this range with a much higher peak intensity. Moreover, in the case of a composite containing $15 \%$ HAp, a band at a wavelength of about $560-590 \mathrm{~cm}^{-1}$ —characteristic of the triply degenerate bending of $\mathrm{PO}_{4}{ }^{3-}(\mathrm{O}-\mathrm{P}-\mathrm{O})$ - was also observed. Analogous results were obtained both for HAp obtained using method A and HAp obtained using method B. Therefore, it was found that the intensity of the absorption bands originating from the $\mathrm{P}-\mathrm{O}$ stretching vibrations and from the triply degenerate bending of $\mathrm{PO}_{4}{ }^{3-}$ increases with the percentage of the ceramic phase in the composite.

\subsection{Incubation In Vitro}

\subsubsection{Electroanalytical Analysis-Conductivity}

Using conductivity measurements, the electrolyte conductivity was measured (Figure 3). The conductivity changes with the concentration of ions during incubation in fluids simulating the living environment. These changes indicate the interaction between biomaterial and incubation fluids, and the possibility of ion exchange. Changes were observed in all of the samples, the largest of which were in artificial saliva, in which the samples were decomposed during incubation. In each case, the curves in the graph increased. The fact 
that the total decomposition of the sample was observed during incubation in artificial saliva is directly related to the greatest changes in the conductivity values. This indicates that samples degrade under the given conditions. The increase in conductivity in this case is the result of an increase in the ion concentration due to decomposition. This is particularly noticeable for the WPI 0 sample, which is the polymer matrix itself. The situation is different for incubation in SBF, where changes were also observed; however, they are relatively small. This proves the relative stability of materials in this liquid. The changes observed in Ringer's fluid are probably dependent on the fact that the partial resorption of the material was observed; however, due to the presence of certain amounts of calcium and phosphate in the composition of the fluid, remineralization on the surface of the biomaterial was also observed. The greatest stability of samples was observed for incubation in distilled water. Such stability is associated with the absence of other ions in the solution with which the biomaterial could interact.

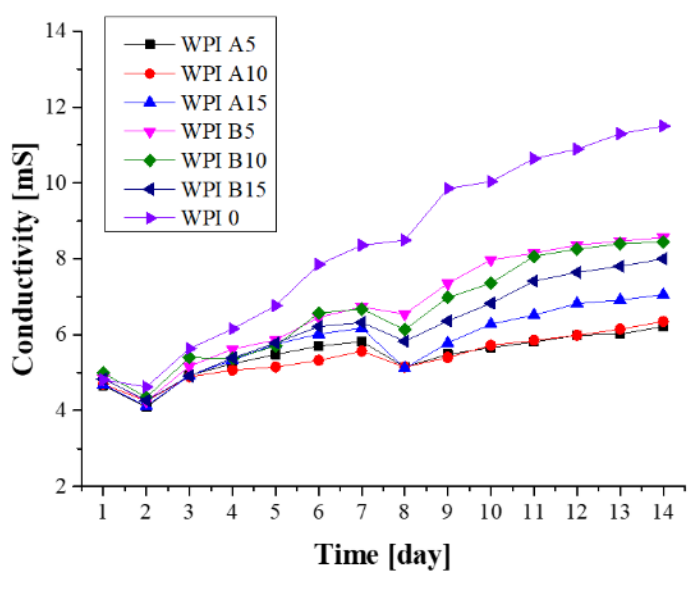

(a)

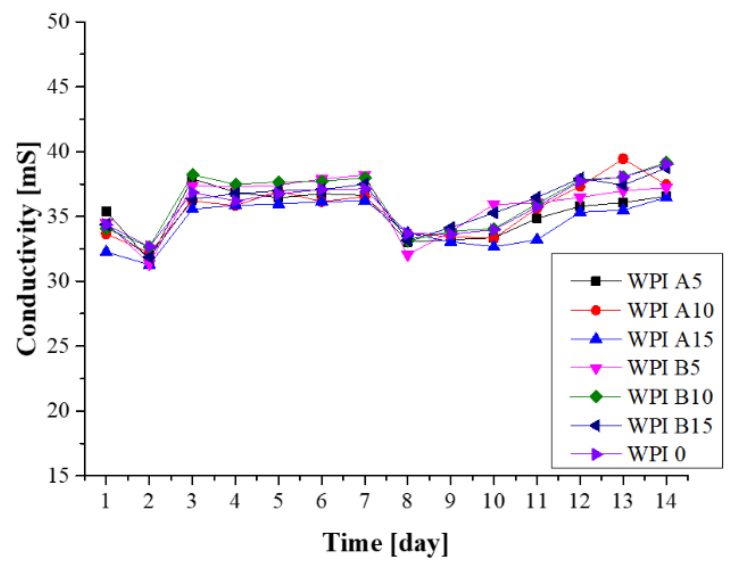

(c)

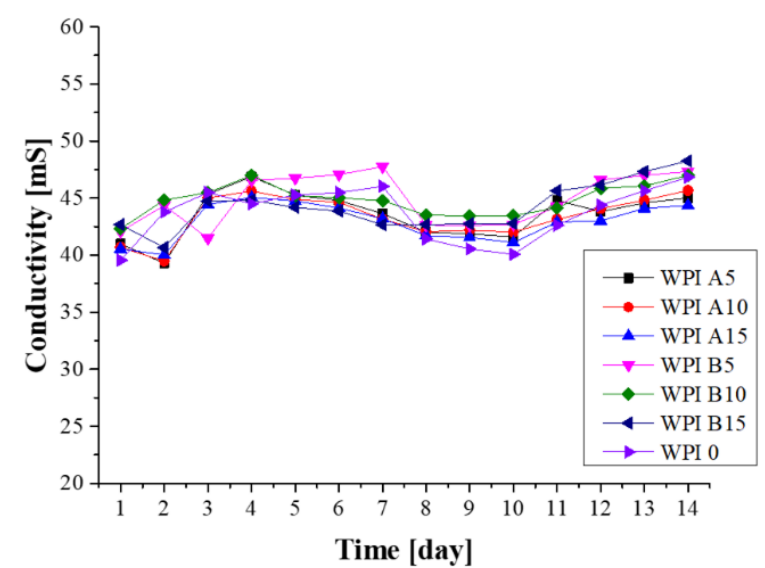

(b)

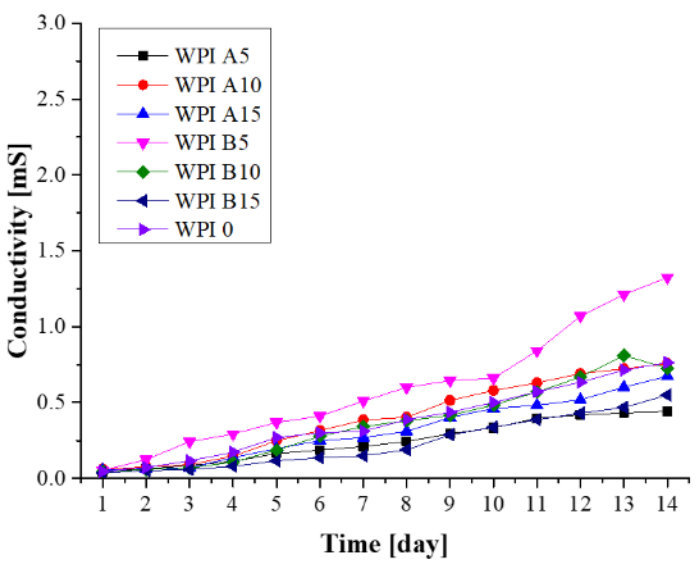

(d)

Figure 3. Conductivity analysis of hydrogels during a 14-day incubation in fluids simulating the biological environment: (a) incubation in artificial saliva; (b) incubation in SBF; (c) incubation in Ringer's fluid; (d) incubation in distilled water. 


\subsubsection{Electrochemical Analysis-Potentiometry}

A potentiometric analysis was performed in order to determine the $\mathrm{pH}$ change of the solutions in which the samples were incubated (Figure 4). This measurement allows the determination of the stability of the material in the chosen solution, and is closely related to conductivity analysis. Repeatedly, the greatest changes were observed during incubation in artificial saliva, in which the samples degraded. A significant change in $\mathrm{pH}$ value was observed in relation to the initial value of 6.2. As a result of the total degradation, the ions and compounds released from the composites caused a significant increase in $\mathrm{pH}$. The SBF incubation $\mathrm{pH}$ values remained stable between 7.3 and 7.8 throughout the incubation period. With respect to the remaining incubation fluids, the smallest changes were again observed in SBF, which indicates the stability of the sample in this fluid. Additionally, the formation of new apatite layers on the surface, especially in SBF but also in Ringer's solution, may limit the degradation process and thus also limit the rapid change of the $\mathrm{pH}$ value.

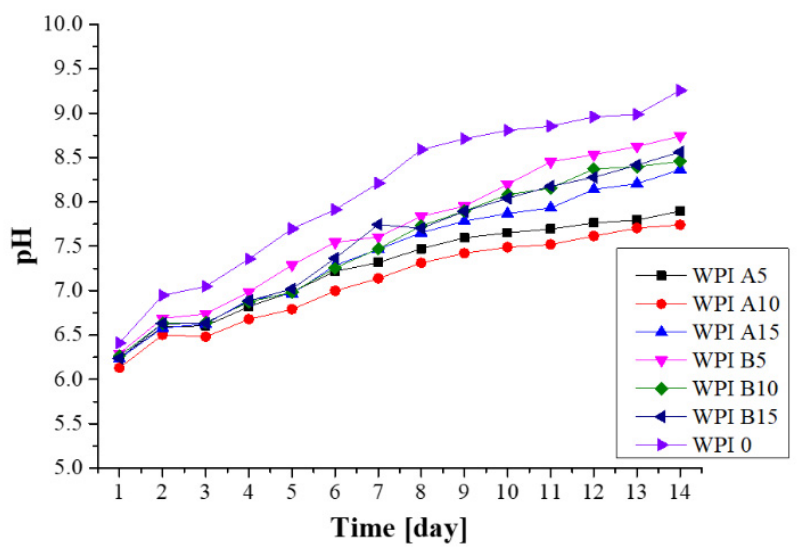

(a)

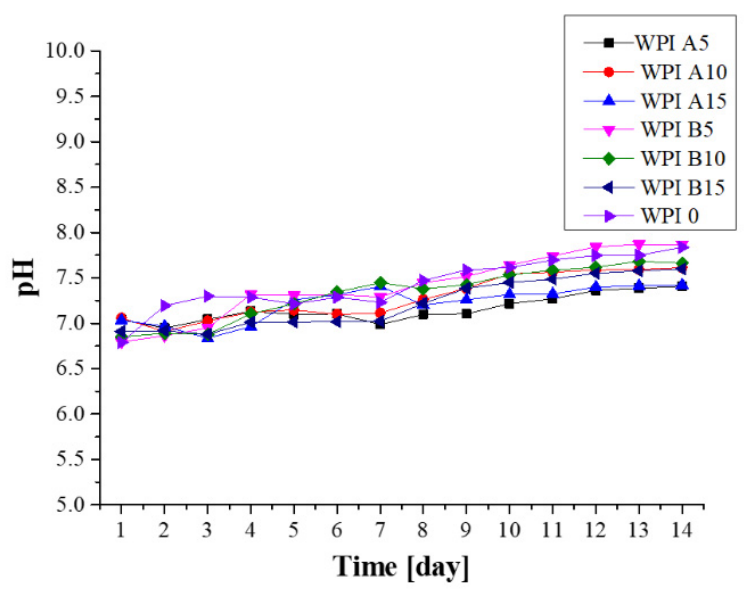

(c)

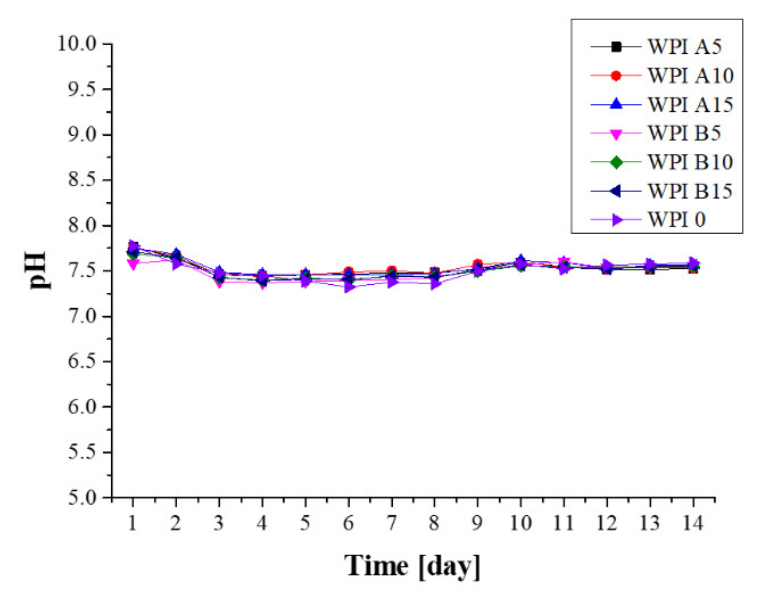

(b)

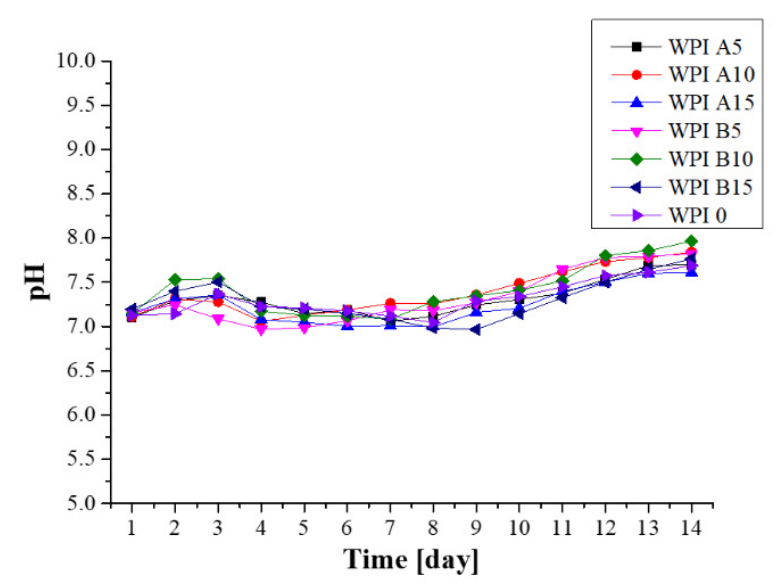

(d)

Figure 4. Potentiometry analysis of the hydrogels during a 14-day incubation in fluids simulating the biological environment: (a) incubation in artificial saliva; (b) incubation in SBF; (c) incubation in Ringer's fluid; (d) incubation in distilled water. 


\subsubsection{Swelling Capacity}

The swelling capacity was determined for unmodified WPI hydrogel and for those with added hydroxyapatites A and B (Figure 5). As a result, the swelling effect of the hydrogel materials was confirmed for all of the tested samples. The analysis was performed in four fluids: artificial saliva, SBF, Ringer's fluid and distilled water. It was observed that, in all of the fluids, unmodified WPI hydrogels had the highest sorption capacity. On the other hand, swelling coefficients decreased with increasing proportion of the ceramic phase, e.g., for WPI A5 and WPI A15 these are 109\% and $82 \%$ (24 h, artificial saliva), respectively. This is most probably related to the presence of the ceramic phase, which fills the free spaces between the polymer chains while limiting the possibility of fluid sorption. In the case of WPI hydrogel without the addition of HAp, there are free spaces between the chains into which the fluid easily penetrates. An analogous relationship was found for all fluids. Moreover, small differences in the swelling coefficients were also observed in each fluid for hydrogels with the addition of HAp obtained by different methods. A higher sorption capacity was found in samples containing hydroxyapatite obtained by method A. According to the previously presented results of the XRD analysis, this powder was characterized by a lower degree of crystallinity than HAp B. Therefore, it can be assumed that the higher sorption capacity of the composites is related to the physicochemical properties of the ceramic phase present in the polymer matrix. Most probably, HAp A-which is more amorphous-was more easily washed out of the polymer, and the remaining free spaces were filled by the absorbed liquid. It is also important that the swelling rates of hydrogels immersed in distilled water are the highest among the fluids studied. This is related to the fact that, in the remaining fluids, there are different ions that can form additional transverse bonds between the polymer chains. As a result, the cross-linking density of the polymer matrix increases while the free space available for the fluids is reduced, which translates into a lower sorption capacity. An increase in the swelling coefficients was observed for all of the samples over time. However, after about $48 \mathrm{~h}$, the next changes were relatively small. On the other hand, the highest swelling rate was observed in the first $24 \mathrm{~h}$. The exception was the unmodified WPI hydrogel, for which the swelling coefficients reached significantly higher values after just $15 \mathrm{~min}$.

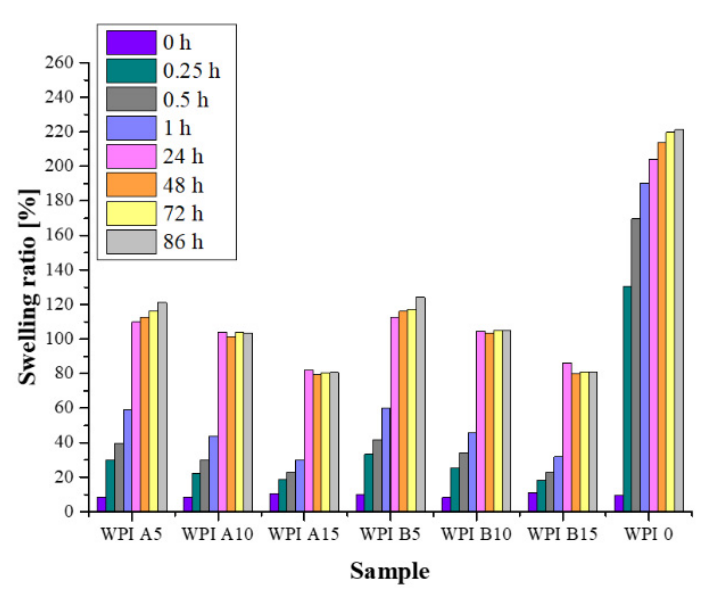

(a)

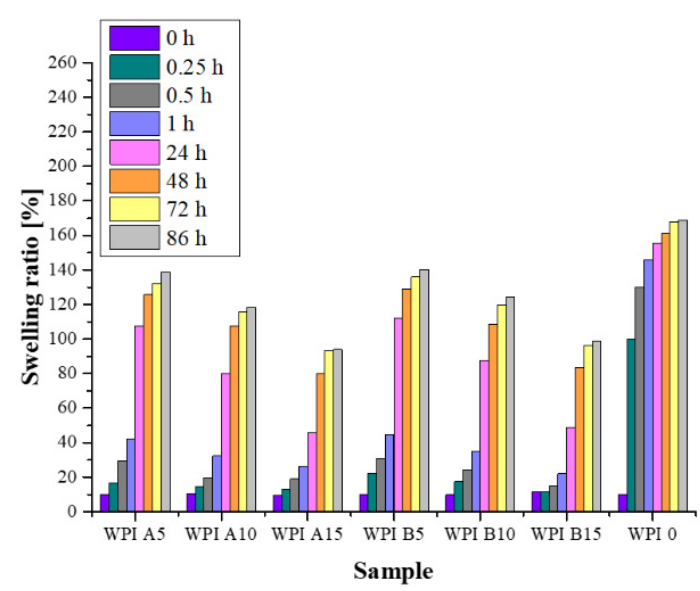

(b)

Figure 5. Cont. 


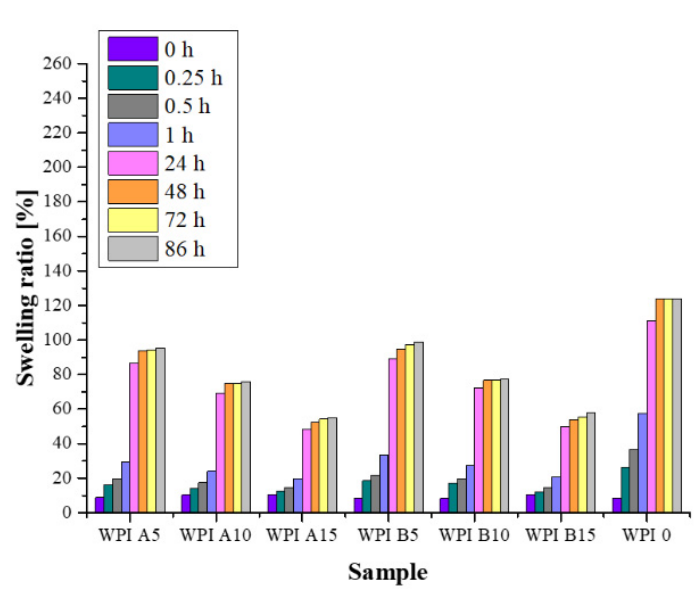

(c)

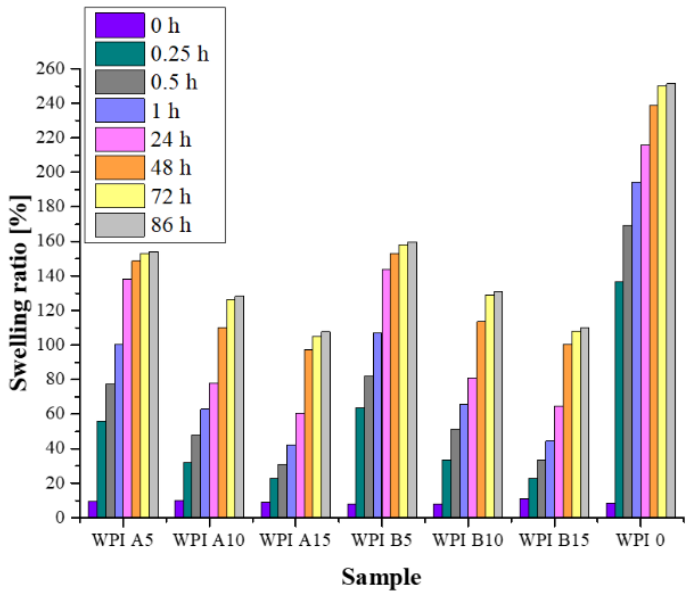

(d)

Figure 5. Swelling ability of hydrogels during a 14-day incubation in fluids simulating the biological environment: (a) incubation in artificial saliva; (b) incubation in SBF; (c) incubation in Ringer's fluid; (d) incubation in distilled water.

\subsection{Morphology Analysis}

\subsubsection{Hydroxyapatite Morphology}

In order to determine the morphologies of the obtained calcium phosphates, an SEM analysis was performed. The SEM images of the HAp obtained by method A are presented in Figure $6 \mathrm{a}$, and those for method B are shown in Figure $6 \mathrm{~b}$. On the basis of the analysis, it was observed that the particles of hydroxyapatite obtained in method A are characterized by a morphology resembling that of powder. HAp B, on the other hand, is characterized by a spherical, flocculated morphology. It is also noticeable that HAp B is a powder consisting of larger agglomerates than HAp A. This information regarding grain size significantly influenced the subsequent incubation stages of the materials, as the durability and resorption of the hydrogel in an in vitro environment depend upon it.

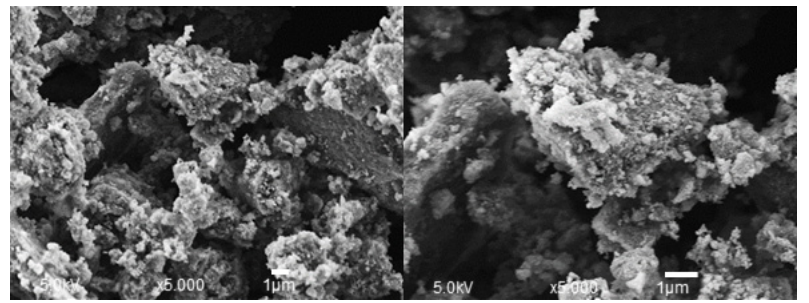

(a)

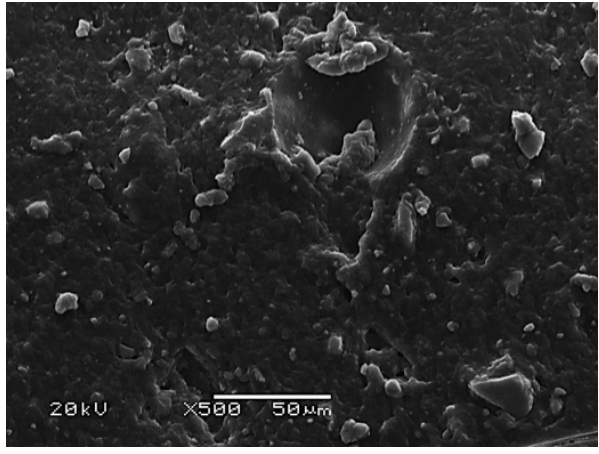

(c)

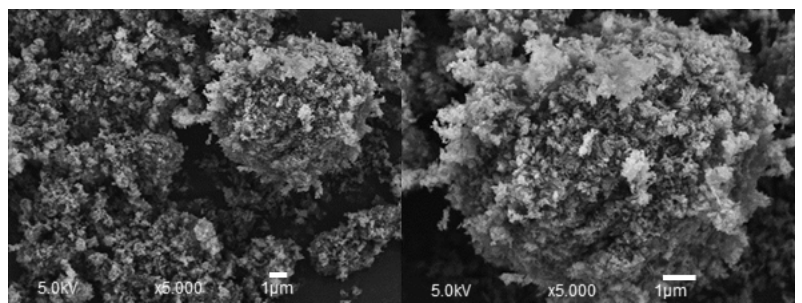

(b)

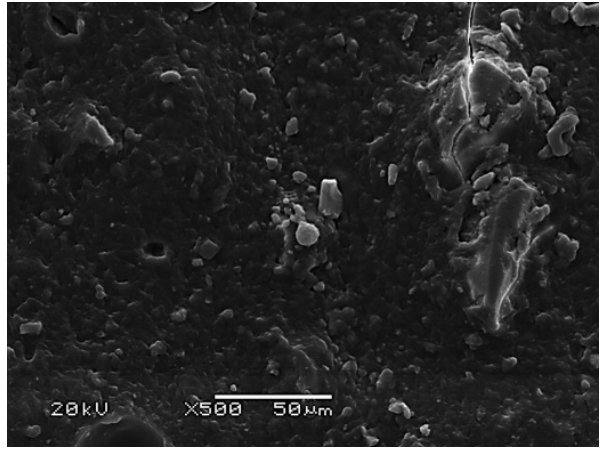

(d)

Figure 6. Cont. 


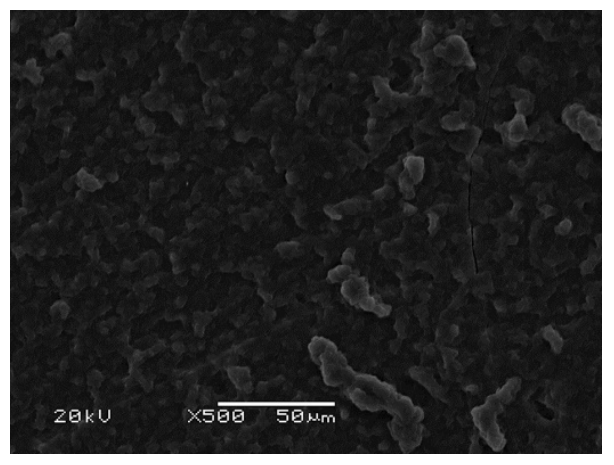

(e)

Figure 6. Morphology analysis of the HAp powders and composite materials before the incubation period: (a) SEM images of hydroxyapatite obtained by method A; (b) SEM images of hydroxyapatite obtained by method B; (c) SEM image of the WPI/HAp A5 composite; (d); SEM image of the WPI/HAp B5 composite; (e) SEM image of a pure WPI hydrogel matrix.

\subsubsection{Hydrogels' Morphology before Incubation}

Figure $6 c$,d shows the surfaces of the composite hydrogels before the incubation in biological fluids. The surface of the hydrogel WPI itself is also presented (Figure 6e). For the composite hydrogels, the presence of HAp powders in the materials is clearly visible, while the surface of the cross-linked WPI itself is relatively smooth. Perceptibly, with an increase in the proportion of the ceramic phase in the hydrogel, the amount of crystals observed during the measurement increases.

\subsubsection{Hydrogels' Morphology after Incubation}

The hydrogels were incubated for a period of 2 weeks in the selected artificial biological fluids. Figure 7a,b presents a comparison of the surface morphology of the WPI A5 and WPI A15 samples together with an EDS microanalysis after incubation in SBF. An analogous comparison was made for WPI B5 and WPI B15 (Figure 7c,d). Similar results were obtained for both cases. In SBF, in the hydrogels with a lower content of the ceramic phase, after incubation the spots where practically pure polymer matrix was present were still visible, and the EDS microanalysis showed only trace amounts of the elements P and Ca. However, in the case of samples with a higher proportion of the ceramic phase, a pure polymer matrix itself could not be seen. The entire surface of the biomaterial was covered with new crystals. In addition, the EDS microanalysis of these samples showed the highest intensity of the peaks for P and Ca in the areas studied.

The appearance of new apatite layers and crystals on the surface of the incubated samples is the most desirable result. Such biomineralisation is a testament to the bioactivity of the WPI/HAp hydrogel due to its confirmation of the interaction between the material and the incubating fluid.

An analogous measurement was carried out for the WPI matrix itself, without ceramic reinforcement. The obtained result is presented in Figure 7e. The lack of apatite crystals on the surface confirms that the WPI protein itself does not promote the formation of apatite layers. Consequently, one would not expect it to demonstrate bioactivity when implanted in bone. 

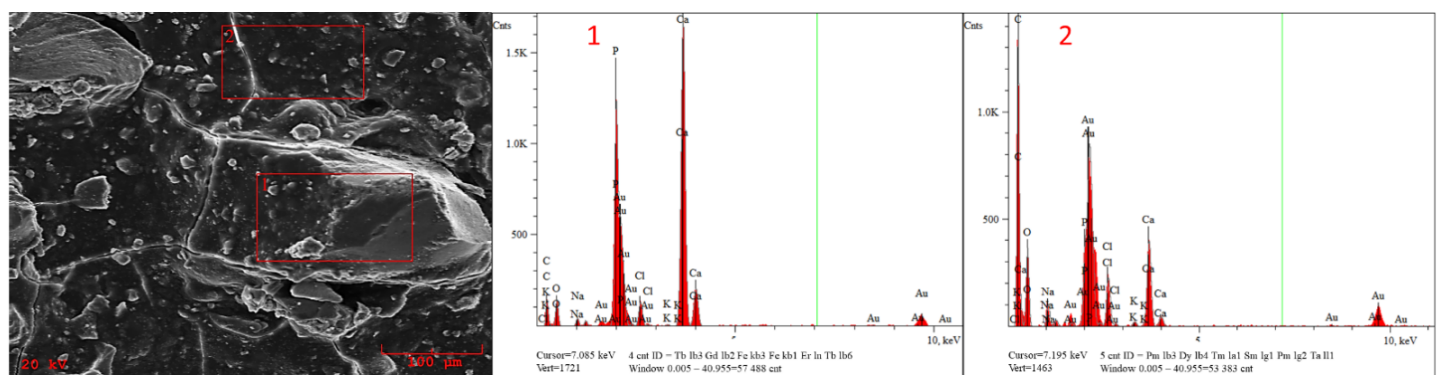

(a)
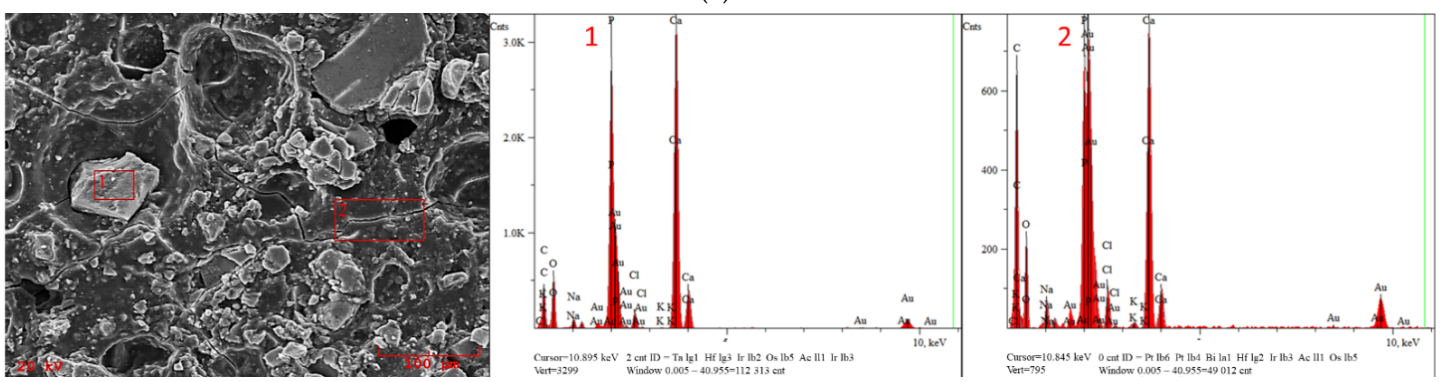

(b)
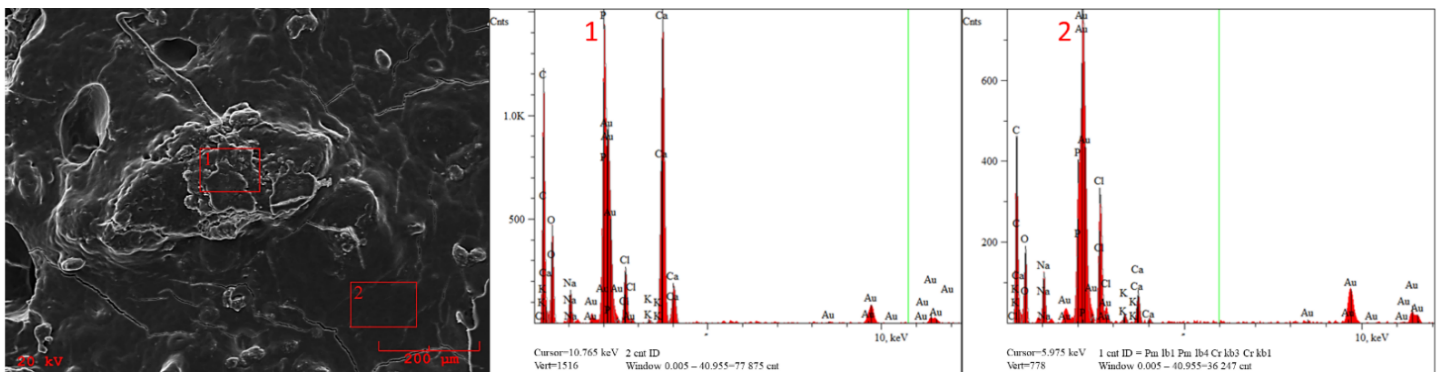

(c)
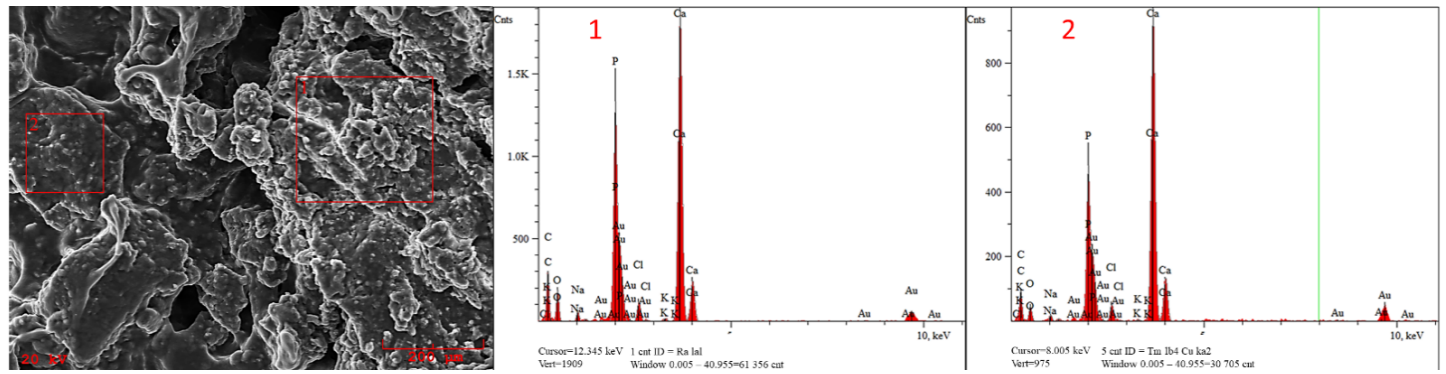

(d)
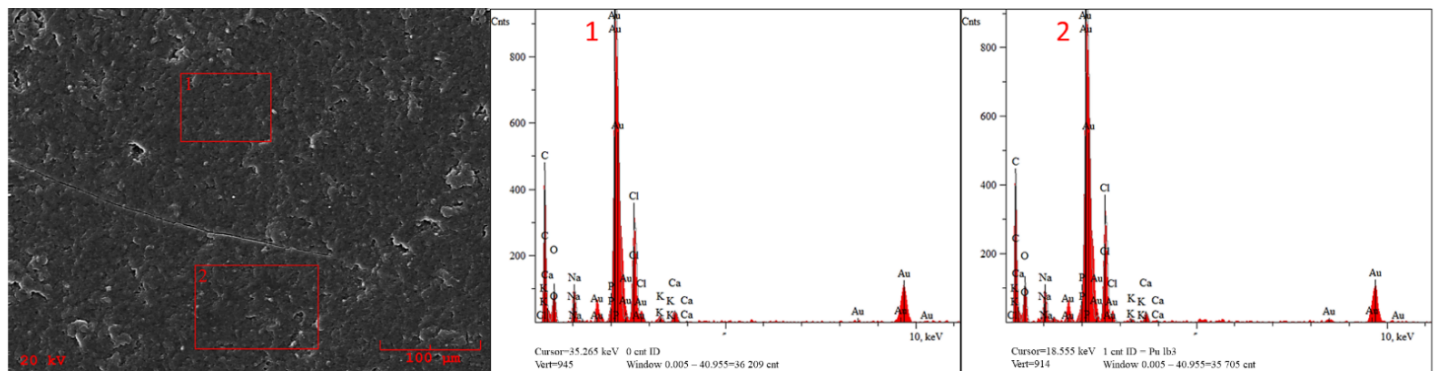

(e)

Figure 7. SEM morphology and EDS microanalysis of the composites and the pure WPI matrix after incubation in SBF: (a) WPI A5; (b) WPI A15; (c) WPI B5; (d) WPI D15; (e) pure WPI hydrogel. 
Therefore, the ability to form mineralized apatite layers on the surface of incubated hydrogels is fully dependent on the presence of HAp in the biomaterial. Accordingly, in materials containing a greater proportion of the ceramic phase, the ability to induce mineralization by new apatite formations will be significantly higher, which would be expected to improve the biocompatibility.

Moreover, a detailed EDS analysis concerning the presence of specific elements is presented in Table 7. The presence of Au in each of the samples is connected with the necessity of gold sputtering before SEM analysis. The presence of $\mathrm{C}$ and $\mathrm{O}$ atoms was noticeable in each sample, which is related to the composition of the polymer matrix. The detection of $\mathrm{Mg}, \mathrm{Na}$ and $\mathrm{Cl}$ ions after the incubation indicates the desired reactions between artificial physiological fluid and biomaterial. The analysis of the elemental composition of hydrogels, especially the amounts of $\mathrm{Ca}$ and $\mathrm{P}$, shows that slightly larger amounts of these elements after the incubation period are observed in samples containing HAp B. In the WPI 0 sample, the amount of these desired elements was negligible.

Table 7. Elemental composition of hydrogels after incubation in SBF.

\begin{tabular}{|c|c|c|}
\hline Sample & Spot & Atomic Percentage (wt.\%) \\
\hline \multirow{2}{*}{ WPI A5 } & 1 & C: 12.8, O: 17.1, Na: 1.1, Mg: 0.5, P: 16.9, Cl: 2.5, K: 0.2, Ca: 38.9, Au: 10.0 \\
\hline & 2 & C: 46.7, O: 22.4, Na: 1.6, Mg: 0.4, P: 5.6, Cl: 2.6, K: 0.4, Ca: 10.8, Au: 9.5 \\
\hline \multirow{2}{*}{ WPI A15 } & 1 & C: $19.1, \mathrm{O}: 24.4, \mathrm{Na}: 1.1, \mathrm{Mg}: 0.5, \mathrm{P}: 16.2, \mathrm{Cl}: 1.3, \mathrm{~K}: 0.1$, Ca: 30.3, Au: 7.2 \\
\hline & 2 & C: 39.8, O: 19.9, Na: 1.5, Mg: 0.4, P: 8.3, Cl: 1.7, K: 0.3, Ca: 15.8, Au: 12.3 \\
\hline \multirow{2}{*}{ WPI B5 } & 1 & C: 8.8, O: 20.6, Na: 1.1, Mg: 0.6, P: 20.6, Cl: 2.0, K: 0.1, Ca: 39.9, Au: 6.3 \\
\hline & 2 & C: 48.3, O: 24.0, Na: 1.9, Mg: 0.4, P: 3.8, Cl: 3.0, K: 0.4, Ca: 6.6, Au: 11.6 \\
\hline \multirow{2}{*}{ WPI B15 } & 1 & C: 22.1, O: 18.7, Na: 1.2, Mg: 0.2, P: 14.7, Cl: 1.8, K: 0.3, Ca: 34.5, Au: 6.5 \\
\hline & 2 & C: $17.4, \mathrm{O}: 14.5, \mathrm{Na}: 1.0, \mathrm{Mg}: 0.4, \mathrm{P}: 13.5, \mathrm{Cl}: 2.0, \mathrm{~K}: 0.3, \mathrm{Ca}: 43.6, \mathrm{Au}: 7.3$ \\
\hline \multirow{2}{*}{ WPI 0} & 1 & C: 40.8, O: 13.6, Na: 3.3, Mg: 0.3, P: 0.6, Cl: 9.9, K: 0.8, Ca: 1.4, Au: 29.3 \\
\hline & 2 & C: $40.2, \mathrm{O}: 14.9, \mathrm{Na}: 3.4, \mathrm{Mg}:$ 0.5, P: 1.2, Cl: 9.7, K: 0.5, Ca: 1.1, Au: 28.5 \\
\hline
\end{tabular}

Analogously to the previous samples, the morphology and elemental composition of hydrogels incubated in Ringer's solution and distilled water were determined. In the case of samples incubated in artificial saliva, the full degradation of the material made SEM/EDS analysis impossible. This process was probably caused by the acidic nature of the fluid. Furthermore, the total decomposition may be associated with the hydrolytic degradation of the polymer, as the ions present in artificial saliva may contribute to the acceleration of this process [43,44].

However, the partial degradation of the polymer matrix was also observed for the samples incubated in Ringer's solution. The SEM images of the selected hydrogels after incubation in Ringer's solution and distilled water are presented in Figure 8.

On the surface of the samples incubated in Ringer's fluid, ceramic crystals can be observed; however, this is probably the hydroxyapatite placed in the hydrogel before the incubation process began. This conclusion is based on the fact that during the incubation period, the biomaterial significantly reduced its volume. This is most likely due to the partial degradation of the protein matrix due to the slightly acidic nature of the fluid. In the case of incubation in distilled water, there are only single points indicating the presence of the ceramic phase. It can therefore be concluded that the formation of new apatite layers depends on both the percentage of the ceramic phase and the incubation environment. Distilled water, in which no $\mathrm{Ca}$ and $\mathrm{P}$ ions are present, is an environment which interacts poorly with the tested biomaterial. As the content of the selected ions increases, these interactions also increase, as was observed in the case of Ringer's fluid and the SBF solution. 


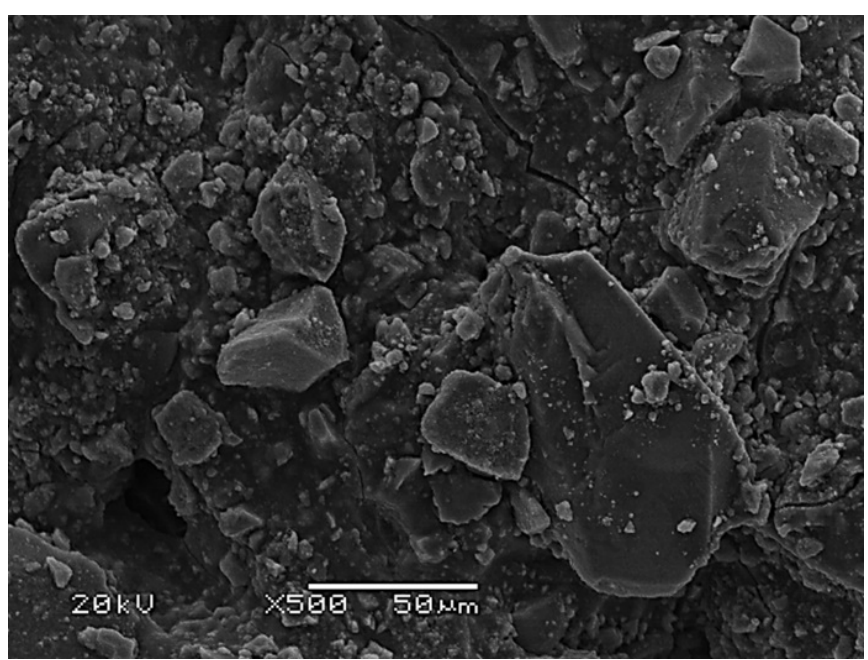

(a)

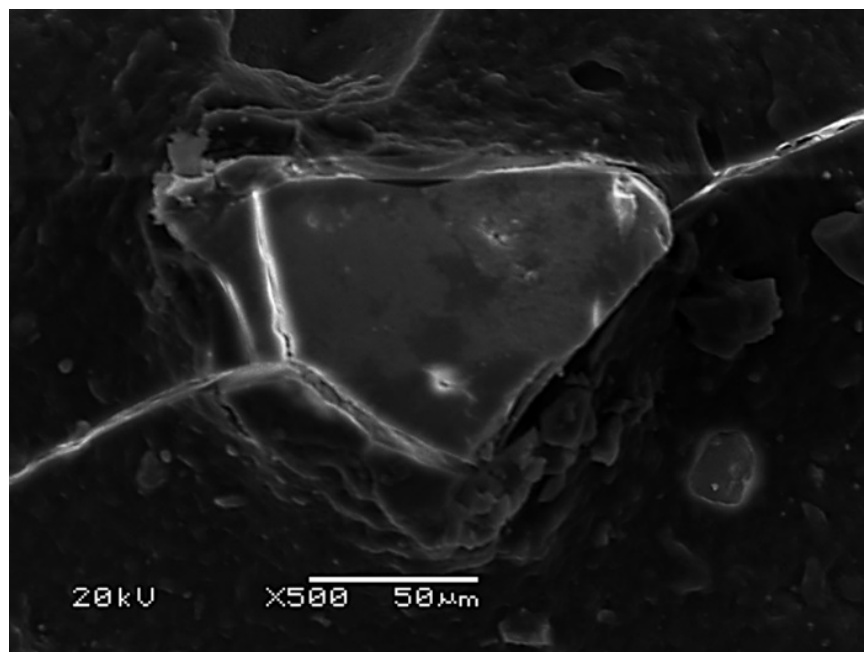

(c)

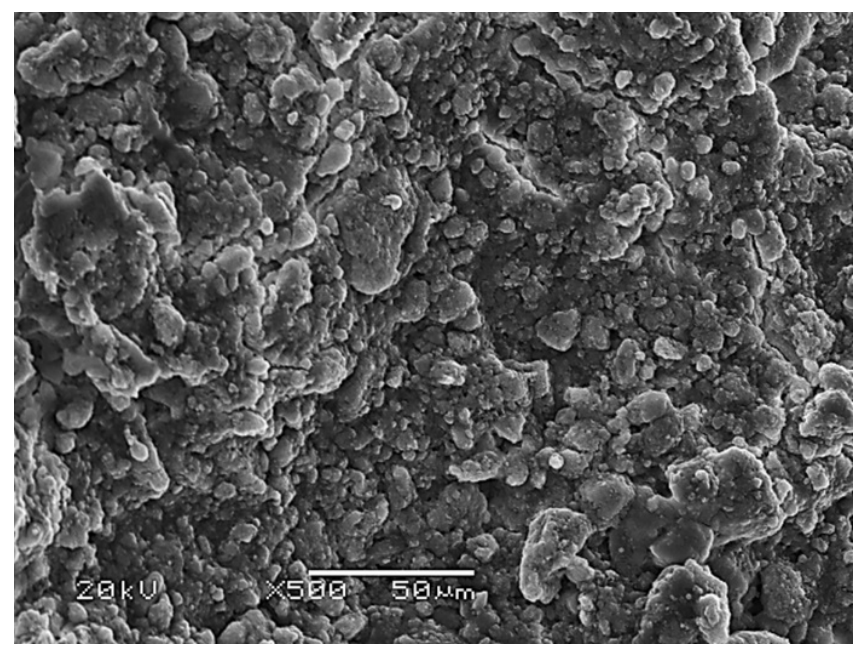

(b)

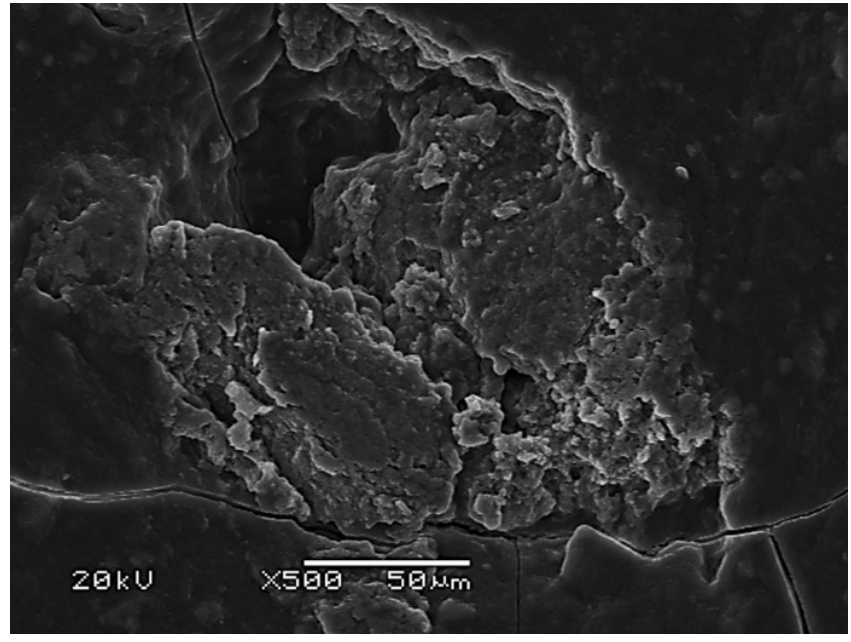

(d)

Figure 8. (a) SEM morphology of WPI A15 after incubation in Ringer's fluid; (b) SEM morphology of WPI B15 after incubation in Ringer's fluid; (c) SEM morphology of WPI A15 after incubation in distilled water; (d) SEM morphology of WPI B15 after incubation in distilled water.

\subsection{Stability Measurements}

The stability of the hydroxyapatite suspension was determined by measuring the sedimentation rate of HAp particles in distilled water and in a $40 \%$ WPI solution. The measurement was performed for both HAp A and HAp B under the conditions presented in Table 8.

Table 8. Conditions for the determination of the stability of the suspension.

\begin{tabular}{ccccc}
\hline Hydroxyapatite & Weight $(\mathrm{g})$ & $\mathrm{V} \mathrm{H}_{\mathbf{2}} \mathbf{O}(\mathrm{mL})$ & Measurement Temperature $\left({ }^{\circ} \mathrm{C}\right)$ & $\mathrm{Cp}(\%)$ \\
\hline A & 0.0440 & 3 & 25 & 1.279 \\
B & 0.0404 & 3 & & 1.328 \\
\hline
\end{tabular}


The results of the analysis performed in distilled water are presented in Figure $9 \mathrm{a}, \mathrm{b}$ (HAp A) and Figure 9c,d (HAp B). In both cases, 20 measurements were taken with an interval of $15 \mathrm{~s}$ within $5 \mathrm{~min}$. The transmission value increasing with time indicates a sedimentation process taking place. This increase occurs to the greatest extent at the highest position value; it indicates the gradual clarification of the suspension in the upper part of the measuring vessel. A significant increase in the backscattering at low position values, i.e., at the lower part of the measuring vessel, indicates the accumulation of falling HAp particles. In the case of HAp B, the transmission values are higher than for HAp A. Because the larger the particle diameter, the higher the sedimentation rate, it can be assumed that HAp B is characterized by a larger size of individual particles, which fall faster. In the case of HAp A, the changes in the transmission are also irregular, but the curves in the graph are less wavy than for HAp B. The course of the curves in the graph proves that sedimentation does not occur uniformly in the entire volume. Therefore, it can be concluded that the analyzed suspension is more monodispersive for HAp A than for B.

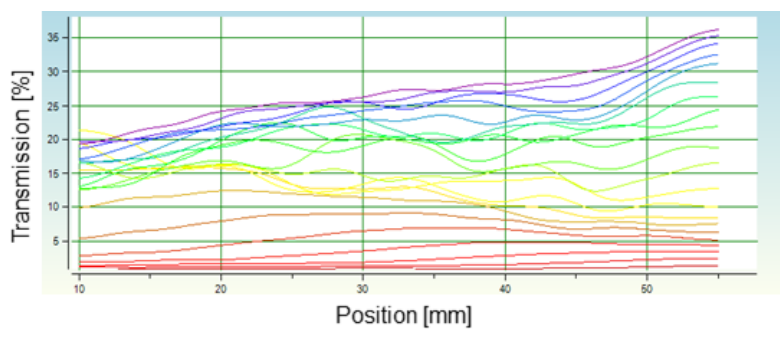

(a)

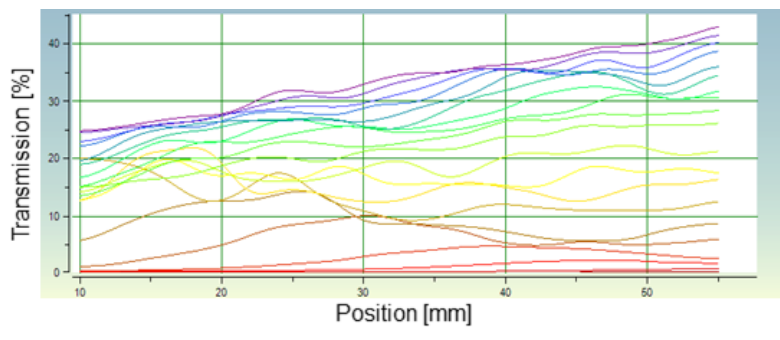

(c)

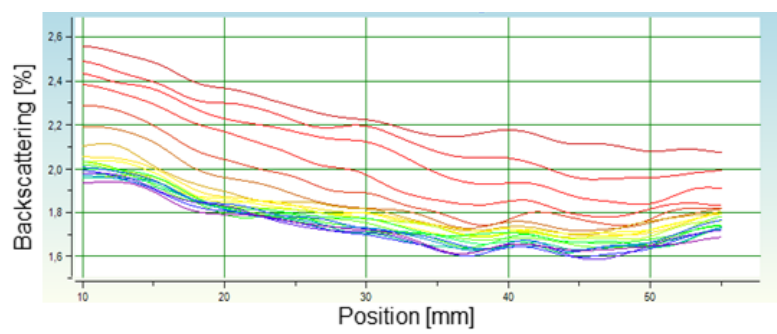

(b)

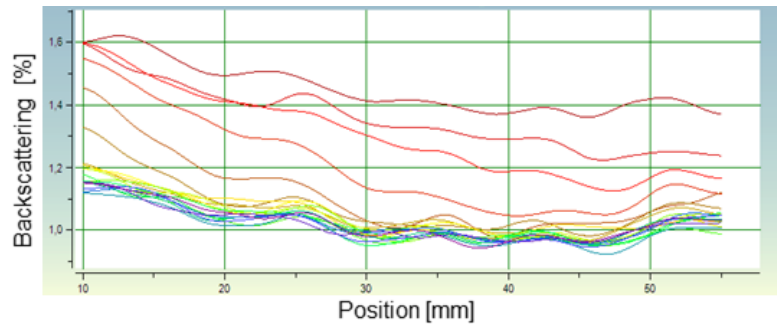

(d)

Figure 9. Analysis of the stability of the HAp A and HAp B suspensions in distilled water: (a) transmission of HAp A; (b) backscattering of HAp A; (c) transmission of HAp B; (d) backscattering of HAp B.

An analogous measurement was also performed for both HAp preparations in a $40 \%$ WPI solution. In this case, 20 measurements were taken with an interval of $90 \mathrm{~s}$. Based on the analysis carried out, a migration front was determined for all of the samples, which made it possible to determine the sedimentation rate of the HAp particles in distilled water and a WPI solution. The sedimentation rates determined on the basis of the migration front graphs are presented in Table 9.

Table 9. Sedimentation rate for HAp powder in different solutions.

\begin{tabular}{ccc}
\hline Suspension & HAp & Sedimentation Rate [mm/min] \\
\hline \multirow{2}{*}{ Distilled water } & HAp A & $-12.320 \pm 1.003$ \\
& HAp B & $-35.130 \pm 2.147$ \\
\hline \multirow{2}{*}{ WPI solution } & HAp A & $-0.050 \pm 0.037$ \\
& HAp B & $-0.110 \pm 0.022$ \\
\hline
\end{tabular}

The sedimentation rate is directly proportional to the size and mass of the falling particles, and inversely proportional to the liquid viscosity. This means that th esedimentation increases with particle size and weight, and with the decreasing viscosity of the 
liquid in which they are dispersed. The sedimentation rate of HAp in 40\% WPI solution is much lower than the rate of their sedimentation in distilled water, which is connected with the higher viscosity of the WPI solution. In the case of composites consisting of a polymer and ceramic phase, this is an important fact because increasing the viscosity of the WPI solution offers the possibility of obtaining a more homogeneous system than in the case of a low viscosity solution, in which rapid particle sedimentation occurs. The sedimentation rate of HAp particles in the WPI solution is $0.05016 \mathrm{~mm} / \mathrm{min}$ for HAp A and $0.1101 \mathrm{~mm} / \mathrm{min}$ for HAp B, respectively. This means that the gelation process that takes place in $7 \mathrm{~min}$ is fast enough to prevent the significant sedimentation of HAp particles. In the case of sedimentation in distilled water, the HAp particles fall much faster, and the sedimentation rate values indicate a faster drop of HAp B particles. Using the relationship between particle size and falling speed, the analysis also allowed the determination of the average diameter of the hydroxyapatite particles in the suspension. The diameters were determined for the HAp samples in distilled water (assumed parameters: particle density $3.2 \mathrm{~g} / \mathrm{cm}^{3}$; solvent density $0.9982 \mathrm{~g} / \mathrm{cm}^{3}$; solvent viscosity $1.002 \mathrm{mPa}$; particle volume Conc. HAP A: $1.279 \%$, HAp B: $1.328 \%$ ). The average diameter of the HAp A particles was $\varnothing=0.7245 \mu \mathrm{m}$, while HAp B was $\varnothing=0.9631 \mu \mathrm{m}$. These results are consistent with the conclusions drawn from the SEM images, according to which, in the case of single grains, the HAp A particles are smaller in size.

\subsection{The Viability of Cells in the Milieu of the Biocomposites}

The influence of biocomposites containing WPI hydrogels with HAp A or HAp B on the viability of the reference L-929 mouse fibroblasts was assessed in the MTT reduction assay, which verified the metabolic activity of mitochondrial dehydrogenases in the environment of the tested substances. In this test, the biochemical activity of mitochondrial enzymes positively correlated with cell viability. As shown in Figure 10a, the viabilities of murine fibroblasts exposed to WPI 0, WPI 5A, WPI 10A and WPI 15A were found to be $70 \pm 12 \%, 98 \pm 15 \%, 101 \pm 25 \%$ and $74 \pm 13 \%$, respectively. A statistical analysis showed that WPI modified with HAp A and HAp B did not reduce significantly the metabolic activity of L-929 cells when compared with the physiological viability of the control cells.

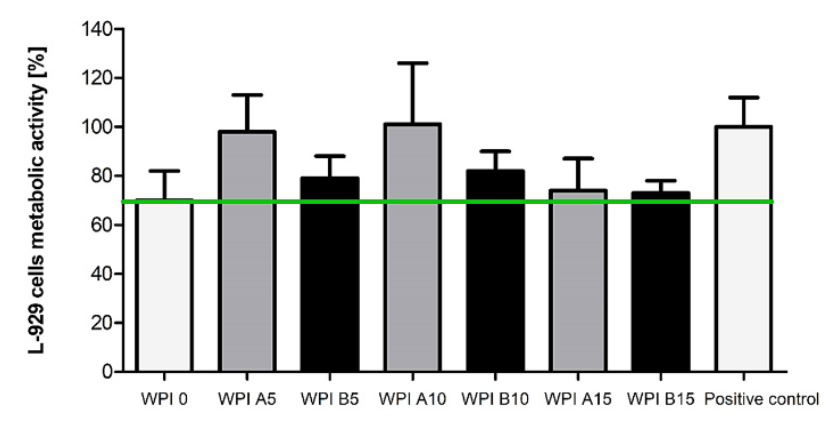

(a)

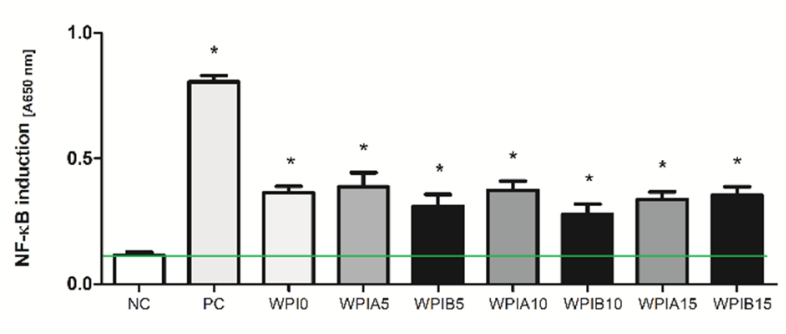

(b)

Figure 10. (a) The viability of murine fibroblasts L-929 after $24 \mathrm{~h}$ incubation with WPI modified HAp A and HAp B biocomposites, evaluated using the 3-(4,5-dimethylthiazol-2-yl)-2,5-diphenyltetrazolium bromide (MTT) reduction assay according to ISO-10993-5:2009. The cells incubated without composites served as a positive control of the viability (100\%). The data are presented as mean \pm SD for the three separate experiments. The green line indicates the minimum level $(70 \%)$ of the cells' metabolic activity required to recognize the biomaterial as non-cytotoxic at the in vitro level; (b) NF- $\mathrm{KB}$ induction in THP1-Blue ${ }^{\mathrm{TM}}$ monocytes incubated for $24 \mathrm{~h}$ with WPI modified HAp A, and HAp B biocomposites. The cells incubated without composites served as a negative control of the monocyte's activation (NC), and monocytes stimulated with S. cerevisiae $\beta$-glucan served as the positive control (PC). The data are presented as the mean \pm SD for the four separate experiments. The green line indicates the physiological level $(0.114 \pm 0.013)$ of the non-stimulated monocytes. ${ }^{*} p$ values $(<0.05)$ calculate in comparison to the untreated cell cultures. 
A decrease in the metabolic activity was observed only after the incubation of L-929 cells with WPI0 and WPI 15A; however, the cell viability was not reduced below 30\% compared to the control cells. WPI modification with hydroxyapatite B-WPI 0, WPI 5B, WPI 10B and WPI 15B-resulted in the viability of L-929 cells equal to $70 \pm 12 \%, 79 \pm 9 \%$, $82 \pm 8 \%, 73 \pm 5 \%$, respectively. Moreover, it was shown that the mice fibroblasts exposed to WPI composites modified with HAp obtained using precipitation method B exhibited lower metabolic activity in comparison to the untreated cells or cells incubated in the milieu of HAp A-modified WPI composites.

\subsection{The Biocomposite-Mediated Monocyte Activation}

Because monocyte activity is crucial for the induction of a first (inflammatory) stage of the healing process, we attempted to evaluate the WPI-mediated influence of the biocomposites on the NF- $\mathrm{KB}$ induction in THP1-Blue ${ }^{\mathrm{TM}}$ monocytes. It was shown that all of the tested biocomposies containing WPI stimulated the activity of monocytes in comparison to the untreated cell cultures $\left(p<0.05^{*}\right)$, and this effect occurred regardless of modification with HAp A or HAp B (Figure 10b). In addition, when the results were analyzed with ANOVA with Tukey's post-hoc test, it was shown that the WPI A5 (0.388 \pm 0.056$)$, WPI A10 (0.374 \pm 0.036$)$, WPI A15 (0.337 \pm 0.030$)$ and WPI B5 (0.310 \pm 0.047$)$, WPI $\mathrm{B} 10(0.279 \pm 0.039)$ and WPI B15 $(0.354 \pm 0.034)$ biocomposites induced higher monocyte activation than that observed for the positive control $(0.852 \pm 0.015 ; p<0.05 \#)$.

\section{Discussion}

Composites based on polymers reinforced with HAp are materials known to be applied in the regeneration of the skeletal system. However, it seems crucial to choose an appropriate polymer phase, and a type of ceramic with suitable properties. In this study, two methods of ceramic synthesis were selected in order to produce two different hydrogel composite materials. Both presented methods resulted in the synthesis of ceramics which were confirmed to be HAp by FT-IR analysis. However, it was confirmed that their physicochemical parameters were slightly different. Depending on preferences, a material with a larger or smaller grain diameter can be obtained. The degree of crystallinity determined by the XRD also varied. The method used to obtain HAp B, due the elevated temperature at which it is conducted, results in a product with a higher degree of crystallinity than HAp A, which is obtained at room temperature. The difference in the density or grain size of the powders obtained was observed by SEM analysis and by measurements with the Multiscan MS20. The analysis of migration front and sedimentation rate clearly indicates a larger grain diameter for HAp B. Moreover, the powders were shown to be medium monodispersive. The sedimentation rates were also determined in WPI solutions in order to select the appropriate polymer concentration for hydrogel synthesis.

Both hydroxyapatite A and B were used to synthesize WPI hydrogels in order to assess the influence of equal types of these ceramics on hydrogel behavior. Despite slight differences in the physicochemical parameters of HAp, the hydrogels behaved similarly during incubation. A process of biomineralization was used to assesses the mineralization of hydrogels as a predictor of bioactivity, and to study the influence of the substrate composition on the process of biomineralization in in vitro conditions. Hydrogel materials containing the ceramic phase HAp A, the ceramic phase HAp B and no ceramic phase were examined. Four incubation fluids were selected, including distilled water, SBF, artificial saliva and Ringer's fluid. It was determined that the WPI matrix itself does not demonstrate the desired bioactivity; however, the addition of the ceramic phase raises it. The strongest promotion of mineralization was observed for hydrogels WPI A15\% and WPI B15\% incubated in SBF. This is clearly visible in the pictures of the SEM analysis. The 15\% composites showed the highest bioactivity, as the new apatite layers were more frequently observed there compared to the other samples. Furthermore, the EDS microanalysis indicated that after barely two weeks of incubation, there are no places without layers of apatite on the surface of the material. This effect is closely related to the nature and the 
composition of SBF, as the formation of new apatite layers in this liquid is highly dependent on the presence of calcium ions and their interactions [45]. Furthermore, the conductivity and potentiometry measurements indicated interactions between biomaterials and the incubation environment. The clear changes and increases in value in artificial saliva are associated with an acid reaction of this fluid, which was too aggressive for the protein matrix and caused its complete degradation. Minor changes in the case of SBF suggest the stability of hydrogels in this environment. Moreover, the swelling capacity analysis confirmed the potential use of composites in drug delivery systems. The highest swelling coefficients were observed for distilled water. In addition, a higher swelling capacity was shown for materials without a ceramic phase, which is related to the fact that there are more free spaces between the polymer chains. However, even a smaller increase observed for materials containing $15 \%$ ceramics is a promising outcome.

The conducted microbiological analysis also yielded satisfactory results and confirmed the safety and application potential of the presented materials, as biomaterials are considered safe on an in vitro level in the absence of biomaterial-mediated cytotoxic activity. In this study, we have shown that hydrogel materials consisting of WPI with a ceramic phase of HAp A or HAp B met the ISO 10993-5: 2009 criterion for maintaining the in vitro viability of at least $70 \%$ of the cells exposed to the biomaterial. Moreover, the presented results are consistent with the current results reported by other authors. The non-toxic nature of whey protein-based hydrogels was confirmed on the mouse pre-adipose 3T3-L1 and myoblast C2C12 cell lines [46]. Dziadek et al. showed that WPI-hydrogel modified with alpha-tricalcium phosphate $(\alpha-\mathrm{TCP})$, one of the most chemically reactive forms of bioactive calcium phosphate $(\mathrm{CaP})$ ceramics, do not reduce the cell viability of human osteoblast-like MG-63 after 3 days of stimulation in a direct contact cytotoxicity assay. On the other hand, after a 7-day culture on WPI hydrogel modified with $\alpha$-TCP, osteoblast-like cells showed higher metabolic activity [47]. The experiments of Gupta et al. showed that argonite-modified WPI hydrogels with different pore diameters promoted osteoblast proliferation in a resazurin reduction assay over a 3-week culture period [41]. Although the properties of HAp may appear similar because they share the same chemical formula, the way they are synthesized and processed may affect their biological properties. In our study, we also showed that WPI composites modified with HAp obtained by precipitation method $B$ induced lower metabolic activity in fibroblast cultures, in comparison to untreated cells or cells incubated in the milieu of HAp A-modified WPI composites. It was shown previously by other authors that size, structure and pore diameters influence hydroxyapatite biocompatibility, and it was assumed that the differences in the HAp synthesis methods (A vs. B) influenced the viability of the target cells. Zhao et al. demonstrated that nanosized needle-shaped and plate-shaped hydroxyapatite induced higher cytotoxicity than sphere-shaped and rod-shaped hydroxyapatite [48].

Apart from the lack of cytotoxicity, newly developed composites should exhibit features favoring the healing process. Monocytes are the first immune cells that appear at the site of an injury. They are involved in healing processes, tissue rearrangement, and-due to secretion of cytokines and chemokines-they regulate immune-tissue homeostasis [49]. Injured tissue is rich in signals and cells that propagate the inflammatory response; this stage, although dynamic and acute, is crucial to attract and activate monocytes in the site of implantation. Moreover, monocytes attracted to local bone injuries transform into macrophages, which stimulates osteogenic cells to promote mineralization and induce osteogenesis [50,51]. The role for monocytes in the post-implantation processes and their activity is crucial for the clearance of damaged cells and dis-integrated tissues from the site of the injury. This process is facilitated when monocytes are already in an activated state, which might be obtained by biological modifications of the biocomposites. Recently, the ability of pathogen recognition receptor ligands to skew the immune response in a specific direction was shown. Khokhani and colleagues successfully used nucleic acidbased ligands as osteo-immunomodulators, which favor early osteogenic differentiation without inducing an exaggerated immune-cell-mediated response [52]. 
The immunomodulatory properties of whey proteins are known; however, we have shown, for the first time, that WPI hydrogels modified with HAp activate THP1-Blue ${ }^{\mathrm{TM}}$ monocytes via the NF- $k B$ transcription factor. WPI hydrogels modified with HAp A and HAp B may promote the regeneration process by monocyte migration and activation at the site of bone fraction/implantation. In order to fully address the question of whether WPI-mediated immunostimulation facilitates regeneration processes, further experiments will be conducted. The materials merit further study.

\section{Conclusions}

In this study, we fabricated composite hydrogels by a gelation method at an elevated temperature. Two types of hydroxyapatites, slightly different from each other in terms of their physicochemical properties, were used for this purpose. The combination of bioactive ceramics and WPI with a very high biological value provided a material with satisfactory properties. The results obtained from the physicochemical and biological characterizations presented in this study suggest that such hydrogels constitute a potentially good material for bone tissue regeneration. Thus, this work presents the idea of using low-cost materials with high potential. Depending on the place of implantation and the desired resorption, both of them can be applied.

Further work should focus on further biological studies concerning the influence on bone cell activity and on the sorption potential of the presented hydrogels, and thus their use as a drug and active substances carrier in targeted therapy.

Author Contributions: Conceptualization, A.S.-K., T.E.L.D., D.S. and M.G.; methodology, A.S.-K., B.T., K.R., D.S., M.G.; software, D.S. and M.G.; validation, A.S.-K., B.T. and K.R.; formal analysis, D.S., M.G., M.M.U., P.R.-W., K.M.; investigation, D.S., M.G., M.M.U., P.R.-W., K.M.; resources, A.S.-K., B.T., T.E.L.D. and K.R.; data curation, D.S. and M.G.; writing-original draft preparation, D.S., M.G., M.M.U., P.R.-W.; writing—review and editing, A.S.-K., B.T., T.E.L.D., K.R.; visualization, D.S. and M.G.; supervision, A.S.-K., B.T., T.E.L.D., K.R.; project administration, A.S.-K.; funding acquisition, A.S.-K. All authors have read and agreed to the published version of the manuscript.

Funding: This research was funded by Foundation for Polish Science, grant number POIR.04.04.0000-16D7/18.

Institutional Review Board Statement: Not applicable.

Informed Consent Statement: Not applicable.

Data Availability Statement: The data that support the findings of this study are contained within the article.

Acknowledgments: The "Multifunctional biologically active composites for applications in bone regenerative medicine" project is carried out within the TEAM-NET program of the Foundation for Polish Science financed by the European Union under the European Regional Development Fund. The authors gratefully acknowledge the financial support. T.E.L.D. thanks N8 Agrifood for its financial support in the framework of the pump priming grant "Food2Bone".

Conflicts of Interest: The authors declare no conflict of interest.

\section{References}

1. Baird, J.; Jacob, C.; Barker, M.; Fall, C.H.D.; Hanson, M.; Harvey, N.C.; Inskip, H.M.; Kumaran, K.; Cooper, C. Developmental Origins of Health and Disease: A Lifecourse Approach to the Prevention of Non-Communicable Diseases. Healthcare 2017, 5, 14. [CrossRef]

2. Nugent, R.; Bertram, M.Y.; Jan, S.; Niessen, L.W.; Sassi, F.; Jamison, D.T.; González Pier, E.; Beaglehole, R. Investing in noncommunicable disease prevention and management to advance the Sustainable Development Goals. Lancet 2018, 391, $2029-2035$. [CrossRef]

3. Sözen, T.; Özışık, L.; Başaran, N.C. An overview and management of osteoporosis. Eur. J. Rheumatol. 2017, 4, 46-56. [CrossRef]

4. Ström, O.; Borgström, F.; Kanis, J.A.; Compston, J.; Cooper, C.; McCloskey, E.V.; Jönsson, B. Osteoporosis: Burden, health care provision and opportunities in the EU. Arch. Osteoporos. 2011, 6, 59-155. [CrossRef] [PubMed]

5. Ji, M.-X.; Yu, Q. Primary osteoporosis in postmenopausal women. Chronic Dis. Transl. Med. 2015, 1, 9-13.

6. Mackey, P.A.; Whitaker, M.D. Osteoporosis: A Therapeutic Update. J. Nurse Pract. 2015, 11, 1011-1017. [CrossRef] 
7. Khosla, S.; Hofbauer, L.C. Osteoporosis treatment: Recent developments and ongoing challenges. Lancet Diabetes Endocrinol. 2017, 5, 898-907. [CrossRef]

8. Xiao, W.; Sonny Bal, B.; Rahaman, M.N. Preparation of resorbable carbonate-substituted hollow hydroxyapatite microspheres and their evaluation in osseous defects in vivo. Mater. Sci. Eng. C 2016, 60, 324-332. [CrossRef] [PubMed]

9. Huang, Y.T.; Imura, M.; Nemoto, Y.; Cheng, C.H.; Yamauchi, Y. Block-copolymer-assisted synthesis of hydroxyapatite nanoparticles with high surface area and uniform size. Sci. Technol. Adv. Mater. 2011, 12, 1-7. [CrossRef]

10. Kolmas, J.; Krukowski, S.; Laskus, A.; Jurkitewicz, M. Synthetic hydroxyapatite in pharmaceutical applications. Ceram. Int. 2016, 42, 2472-2487. [CrossRef]

11. Murata, M.; Hino, J.; Kabir, M.A.; Yokozeki, K.; Sakamoto, M.; Nakajima, T.; Akazawa, T. Osteoinduction in Novel Micropores of Partially Dissolved and Precipitated Hydroxyapatite Block in Scalp of Young Rats. Materials 2021, 14, 196. [CrossRef] [PubMed]

12. Quan, H.; He, Y.; Sun, J.; Yang, W.; Luo, W.; Dou, C.; Kang, F.; Zhao, C.; He, J.; Yang, X.; et al. Chemical self-assembly of multi-functional hydroxyapatite with coral-like nanostructure for osteoporotic bone reconstruction. ACS Appl. Mater. Interfaces 2018, 10, 25547-25560. [CrossRef] [PubMed]

13. Arcos, D.; Boccaccini, A.R.; Bohner, M.; Díez-Pérez, A.; Epple, M.; Gómez-Barrena, E.; Herrera, A.; Planell, J.A.; Rodríguez-Mañas, L.; Vallet-Regí, M. The relevance of biomaterials to the prevention and treatment of osteoporosis. Acta Biomater. 2014, 10, 1793-1805. [CrossRef]

14. Germaini, M.M.; Detsch, R.; Grünewald, A.; Magnaudeix, A.; Lalloue, F.; Boccaccini, A.R.; Champion, E. Osteoblast and osteoclast responses to A/B type carbonate-substituted hydroxyapatite ceramics for bone regeneration. Biomed. Mater. 2017, 6, 035008. [CrossRef] [PubMed]

15. Suárez-González, D.; Barnhart, K.; Migneco, F.; Flanagan, C.; Hollister, S.J.; Murphy, W.L. Controllable mineral coatings on PCL scaffolds as carriers for growth factor release. Biomaterials 2012, 33, 713-721. [CrossRef] [PubMed]

16. Family, R.; Solati-Hashjin, M.; Nik, S.N.; Nemati, A. Surface modification for titanium implants by hydroxyapatite nanocomposite. Casp. J. Intern. Med. 2012, 3, 460-465.

17. Corcione, C.E.; Gervaso, F.; Scalera, F.; Montagna, F.; Maiullaro, T.; Sannino, A.; Maffezzoli, A. 3D printing of hydroxyapatite polymer-based composites for bone tissue engineering. J. Polym. Eng. 2017, 37, 741-746. [CrossRef]

18. Bai, X.; Gao, M.; Syed, S.; Zhuang, J.; Xu, X.; Zhang, X.Q. Bioactive hydrogels for bone regeneration. Bioact. Mater. 2018, 3, $401-417$. [CrossRef]

19. Wu, G.; Feng, C.; Quan, J.; Wang, Z.; Wei, W.; Zang, S.; Kang, S.; Hui, G.; Chen, X.; Wang, Q. In situ controlled release of stromal cell-derived factor- $1 \alpha$ and antimiR-138 for on-demand cranial bone regeneration. Carbohydr. Polym. 2018, 182, 215-224. [CrossRef]

20. Wang, X.; Ao, Q.; Tian, X.; Fan, J.; Tong, H.; Hou, W.; Bai, S. Gelatin-based hydrogels for organ 3D bioprinting. Polymers 2017, 9 , 401. [CrossRef]

21. Neubauer, V.J.; Döbl, A.; Scheibel, T. Silk-Based Materials for Hard Tissue Engineering. Materials 2021, 14, 674. [CrossRef]

22. Silva, R.; Fabry, B.; Boccaccini, A.R. Fibrous protein-based hydrogels for cell encapsulation. Biomaterials 2014, 35, 6727-6738. [CrossRef] [PubMed]

23. Wang, Y.; Xue, Y.; Wang, J.; Zhu, Y.; Zhu, Y.; Zhang, X.; Liao, J.; Li, X.; Wu, X.; Qin, Y.-X.; et al. A Composite Hydrogel with High Mechanical Strength, Fluorescence, and Degradable Behavior for Bone Tissue Engineering. Polymers 2019, 11, 1112. [CrossRef] [PubMed]

24. Kang, N.; Hua, J.; Gao, L.; Zhang, B.; Pang, J. The Interplay between Whey Protein Fibrils with Carbon Nanotubes or Carbon Nano-Onions. Materials 2021, 14, 608. [CrossRef]

25. Shang, J.; Liao, M.; Jin, R.; Teng, X.; Li, H.; Xu, Y.; Zhang, L.; Liu, N. Molecular Properties of Flammulina velutipes PolysaccharideWhey Protein Isolate (WPI) Complexes via Noncovalent Interactions. Foods 2021, 10, 1. [CrossRef]

26. Mayorova, A.O.; Jolly, B.C.N.; Verkhovskii, R.A.; Plastun, V.O.; Sindeeva, O.A.; Douglas, T.E.L. pH-Sensitive Dairy-Derived Hydrogels with a Prolonged Drug Release Profile for Cancer Treatment. Materials 2021, 14, 749. [CrossRef]

27. Castro, L.H.A.; de Araújo, F.H.S.; Olimpio, M.Y.M.; de B. Primo, R.B.; Pereira, T.T.; Lopes, L.A.F.; de M. Trindade, E.B.S.; Fer-nandes, R.; Oesterreich, S.A. Comparative Meta-Analysis of the Effect of Concentrated, Hydrolyzed, and Isolated Whey Protein Supplementation on Body Composition of Physical Activity Practitioners. Nutrients 2019, 11, 2047. [CrossRef]

28. Sharma, R.; Shah, N. Health benefits of whey proteins. Nutrafoods 2010, 9, 39-45. [CrossRef]

29. Spotti, M.J.; Tarhan, Ö.; Schaffter, S.; Corvalan, C.; Campanella, O.H. Whey protein gelation induced by enzymatic hydrolysis and heat treatment: Comparison of creep and recovery behavior. Food Hydrocoll. 2017, 63, 696-704. [CrossRef]

30. Gunasekaran, S.; Ko, S.; Xiao, L. Use of whey proteins for encapsulation and controlled delivery applications. J. Food Eng. 2007, 83, 31-40. [CrossRef]

31. Sukhodub, L.B.; Sukhodub, L.F.; Kumeda, M.O.; Prylutska, S.V.; Deineka, V.; Prylutskyy, Y.I.; Ritter, U. C60 Fullerene Loaded Hydroxyapatite-Chitosan Beads as a Promising System for Prolonged Drug Release. Carbohydr. Polym. 2019, $223,115067$. [CrossRef] [PubMed]

32. Gazińska, M.; Kroks, A.; Kobielarz, M.; Włodarczyk, M.; Skibińska, P.; Stępak, B.; Antończak, A.; Morawiak, M.; Płociński, P.; Rudnicka, K. Influence of Hydroxyapatite Surface Functionalization on Thermal and Biological Properties of Poly(l-Lactide)- and Poly(1-Lactide-co-Glycolide)-Based Composites. Int. J. Mol. Sci. 2020, 21, 6711. [CrossRef] [PubMed] 
33. Nawrotek, K.; Tylman, M.; Adamus-Włodarczyk, A.; Rudnicka, K.; Gatkowska, J.; Wieczorek, M.; Wach, R. Influence of chitosan average molecular weight on degradation and stability of electrodeposited conduits. Carbohydr. Polym. 2020, $244,116484$. [CrossRef] [PubMed]

34. Nazarpak, M.H.; Shahabi, S.; Najafi, F. Effect of Gamma Irradiation on Structural and Biological Properties of a PLGA-PEGHydroxyapatite Composite. Sci. World J. 2014, 2014. [CrossRef]

35. Youness, R.A.; Taha, M.A.; Elhaes, H.; Ibrahim, M. Molecular modeling, FTIR spectral characterization and mechanical properties of carbonated-hydroxyapatite prepared by mechanochemical synthesis. Mater. Chem. Phys. 2017, 190, 209-218. [CrossRef]

36. Adzila, S.; Sopyan, I.; Hamdi, M. Mechanochemical synthesis of hydroxyapatite nanopowder: Effects of rotation speed and milling time on powder properties. Appl. Mech. Mater. 2012, 110-116, 3639-3644. [CrossRef]

37. Lala, S.; Satpati, B.; Kar, T.; Pradhan, S.K. Structural and microstructural characterizations of nanocrystalline hydroxyapatite synthesized by mechanical alloying. Mater. Sci. Eng. C 2013, 33, 2891-2898. [CrossRef] [PubMed]

38. Zhou, W.Y.; Wang, M.; Cheung, W.L.; Guo, B.C.; Jia, D.M. Synthesis of carbonated hydroxyapatite nanospheres through nanoemulsion. J. Mater. Sci. Mater. Med. 2008, 19, 103-110. [CrossRef]

39. Pereira, J.O.; Soares, J.; Costa, E.; Silva, S.; Gomes, A.; Pintado, M. Characterization of edible films based on alginate or whey protein incorporated with Bifidobacterium animalis subsp. lactis BB-12 and prebiotics. Coatings 2019, 9, 493. [CrossRef]

40. Gbassi, G.; Yolou, F.; Sarr, S.; Atheba, P.; Amin, C.; Ake, M. Whey proteins analysis in aqueous medium and in artificial gastric and intestinal fluids. Int. J. Biol. Chem. Sci. 2012, 6, 1828-1837. [CrossRef]

41. Gupta, D.; Kocot, M.; Tryba, A.M.; Serafim, A.; Stancu, I.C.; Jaegermann, Z.; Pamuła, E.; Reilly, G.C.; Douglas, T.E.L. Novel naturally derived whey protein isolate and aragonite biocomposite hydrogels have potential for bone regeneration. Mater. Des. 2020, 188, 108408. [CrossRef]

42. Tonyali, B.; Cikrikci, S.; Oztop, M.H. Physicochemical and microstructural characterization of gum tragacanth added whey protein based films. Food Res. Int. 2017, 105, 1-9. [CrossRef] [PubMed]

43. Pagès-Hélary, S.; Andriot, I.; Guichard, E.; Canon, F. Retention effect of human saliva on aroma release and respective contribution of salivary mucin and $\alpha$-amylase. Food Res. Int. 2014, 64, 424-431. [CrossRef] [PubMed]

44. Holz, J.P.; Bottene, M.K.; Jahno, V.D.; Einloft, S.; Ligabue, R. Menthol-loaded PLGA micro and nanospheres: Synthesis, characterization and degradation in artificial saliva. Mater. Res. 2018, 21, 17-24. [CrossRef]

45. Shibata, H.; Yokoi, T.; Goto, T.; Kim, I.Y.; Kawashita, M.; Kikkuta, K.; Ohtsuki, C. Behavior of hydroxyapatite crystals in a simulated body fluid: Effects of crystal face. J. Ceram. Soc. Jpn. 2013, 121, 807-812. [CrossRef]

46. Owonubi, S.J.; Mukwevho, E.; Aderibigbe, B.A.; Revaprasadu, N.; Sadiku, E.R. Cytotoxicity and in vitro evaluation of whey protein-based hydrogels for diabetes mellitus treatment. Int. J. Ind. Chem. 2019, 10, 213-223. [CrossRef]

47. Dziadek, M.; Kudlackova, R.; Zima, A.; Slosarczyk, A.; Ziabka, M.; Jelen, P.; Shkarina, S.; Cecilia, A.; Zuber, M.; Baumbach, T.; et al. Novel multicomponent organic-inorganic WPI/gelatin/CaP hydrogel composites for bone tissue engineering. J. Biomed. Mater. Res. 2019, 107, 2479-2491. [CrossRef] [PubMed]

48. Zhao, X.; Ng, S.; Heng, B.C.; Guo, J.; Ma, L.; Tan, T.T.Y.; Ng, K.W.; Loo, S.C.J. Cytotoxicity of hydroxyapatite nanoparticles is shape and cell dependent. Arch. Toxicol. 2013, 87, 1037-1052. [CrossRef] [PubMed]

49. Baht, G.S.; Vi, L.; Alman, B.A. The Role of the Immune Cells in Fracture Healing. Curr. Osteoporos. Rep. 2018, 16, 138-145. [CrossRef] [PubMed]

50. Ogle, M.E.; Segar, C.E.; Sridhar, S.; Botchwey, E.A. Monocytes and macrophages in tissue repair: Implications for immunoregenerative biomaterial design. Exp. Biol. Med. 2016, 241, 1084-1097. [CrossRef]

51. Kiewiet, M.B.G.; Faas, M.M.; de Vos, P. Immunomodulatory protein hydrolysates and their application. Nutrients 2018, $10,904$. [CrossRef] [PubMed]

52. Khokhani, P.; Rahmani, N.R.; Kok, A.; Öner, F.C.; Alblas, J.; Weinans, H.; Kruyt, M.C.; Croes, M. Use of Therapeutic Pathogen Recognition Receptor Ligands for Osteo-Immunomodulation. Materials 2021, 14, 1119. [CrossRef] [PubMed] 